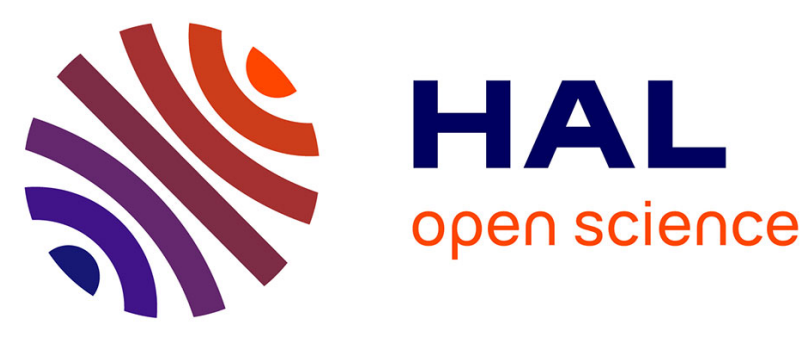

\title{
Luminescence, chiroptical, magnetic and ab initio crystal-field characterizations of an enantiopure helicoidal $\mathrm{Yb}$ ( iii ) complex
}

Frédéric Gendron, Sebastiano Di Pietro, Laura Abad Galán, François Riobé, Virginie Placide, Laure Guy, Francesco Zinna, Lorenzo Di Bari, Amina Bensalah-Ledoux, Yannick Guyot, et al.

\section{To cite this version:}

Frédéric Gendron, Sebastiano Di Pietro, Laura Abad Galán, François Riobé, Virginie Placide, et al.. Luminescence, chiroptical, magnetic and ab initio crystal-field characterizations of an enantiopure helicoidal $\mathrm{Yb}($ iii ) complex. Inorganic Chemistry Frontiers, 2021, 8 (4), pp.914-926. 10.1039/D0QI01194K . hal-03010906

\section{HAL Id: hal-03010906 https://hal.science/hal-03010906}

Submitted on 23 Feb 2021

HAL is a multi-disciplinary open access archive for the deposit and dissemination of scientific research documents, whether they are published or not. The documents may come from teaching and research institutions in France or abroad, or from public or private research centers.
L'archive ouverte pluridisciplinaire HAL, est destinée au dépôt et à la diffusion de documents scientifiques de niveau recherche, publiés ou non, émanant des établissements d'enseignement et de recherche français ou étrangers, des laboratoires publics ou privés. 


\section{Luminescence, Chiroptical, Magnetic and Ab-initio Crystal- Field Characterizations of an Enantiopure Helicoidal Yb(III) Complex}

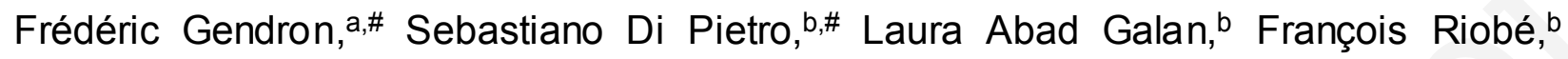
Virginie Placide, ${ }^{\mathrm{b}}$ Laure Guy, ${ }^{\mathrm{b}}$ Francesco Zinna, ${ }^{\mathrm{c}}$ Lorenzo Di Bari, ${ }^{\mathrm{c}, *}$ Amina BensalahLedoux, ${ }^{d}$ Yannick Guyot, ${ }^{d}$ Guillaume Pilet, ${ }^{e}$ Fabrice Pointillart, ${ }^{a}$ Bruno Baguenard, ${ }^{d}$ Stephan Guy, ${ }^{\mathrm{d}, *}$ Olivier Cador, ${ }^{a}$ Olivier Maury, ${ }^{\mathrm{b}, *}$ Boris Le Guennic ${ }^{\mathrm{a}, *}$

[a] Dr. F. Gendron, Dr. F. Pointillart, Pr. O. Cador, Dr. B. Le Guennic

Univ. Rennes, CNRS, ISCR (Institut des Sciences Chimiques de Rennes) - UMR 6226, F-35000 Rennes (France)

E-mail: boris.leguennic@univ-rennes1.fr

[b] Dr. S. Di Pietro, Dr. L. Abad Gallan, Dr. F. Riobé, Dr. L. Guy, Dr. O. Maury

Univ. Ly on, ENS de Ly on, CNRS Laboratoire de Chimie UMR 5182, Université Claude Bernard Ly on 1, F-69342 Ly on, France.

E-mail: olivier.maury @ens-ly on.fr

[c] Dr. F. Zinna, Pr. L. Di Bari

Dipartimento di Chimica e Chimica Industriale, Univ ersità di Pisa, via Moruzzi 13, 56124 Pisa (Italy)

E-mail: Iorenzo.dibari@unipi.it

[d] Dr. B. Baguenard, Dr. A. Bensalah-Ledoux, Pr. S. Guy, Dr. Y. Guy ot

Univ. Ly on, Institut Lumière Matière, UMR 5306 CNRS-Univ ersité Claude Bernard Ly on 1, 10 rue Ada Byron, 69622 Villeurbanne Cedex,

France. E-mail: Stephan.guy @univ-ly on1.fr

[e] Dr. G. Pilet

Univ. Ly on, Laboratoire des Multimatériaux et Interf aces (LMI), UMR 5615 CNRS-Univ ersité Claude Bernard Ly on 1, 43 boulev ard du 11 nov embre 1918, 69622 Villeurbanne cedex, France.

\#

These authors contributed equally to the work. 


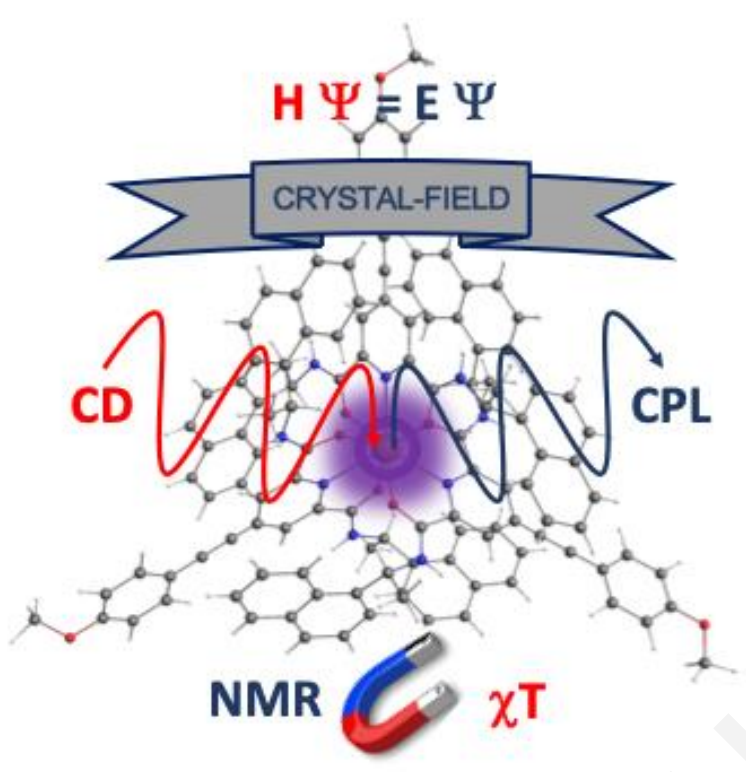

\section{Abstract}

The electronic structure of a chiral $\mathrm{Yb}$ (III)-based complex is fully determined by taking advantage of experimental magnetic, luminescence, and chiroptical (NIR-ECD and CPL) characterizations in combination with ab-initio wavefunction calculations. The combined use of these techniques allows detemining with high resolution the electronic structure diagram as well as the nature of the different states involved in the magnetic and chiroptical properties of the investigated complex. The crystal-field picture deduced from spectroscopic measurements (absorption and emission) is used to reproduce the magnetic properties. Subsequently, advanced ab-initio calculations demonstrate that global chiroptical spectra correspond to the sum of entangled transitions with similar or opposite polarizations. 


\section{INTRODUCTION}

The presence of a partially filled $4 \mathrm{f}$ valence shell in lanthanide(III) ions has been the origin of an incredible rise in the Ln-based chemistry over the past decades. Among the large panel of applications, the most striking use of such complexes can be found in the recent development of new molecular magnets, ${ }^{1}$ named single-molecule magnets (SMMs), which aim at elaborating high density data storage devices, or in the development of Ln(III) luminescent probes for bio-medical purposes. ${ }^{2}$ Additionally, chiral Ln(III)-based complexes have been used lately to achieve circularly polarized luminescence $(\mathrm{CPL})^{3}$ for applications in biological sensing, ${ }^{4}$ anti-counterfeiting devices ${ }^{5}$ and organic light-emitting diodes (CP-OLEDs) for their appealing use in display technology. ${ }^{6}$ In all of these cases, the magnetic, luminescence and chiroptical properties arise from the same origin: the crystal-field (CF) interaction generated by the ligand sphere around the $\mathrm{Ln}(\mathrm{III})$ ion that lifts the degeneracy of the ${ }^{2 \mathrm{~S}+1} \mathrm{~L} J$ ground and excited terms.

Indeed, for an isolated $\operatorname{Ln}(\mathrm{III})$ ion the $4 \mathrm{f}$ transitions are Laporte forbidden, preventing any optical activity due to the vanishing electric transition dipole moments. The presence of a coordination sphere that does not contain an inversion center, allows to (i) break the parity rule and (ii) lift the degeneracy of the ${ }^{2 S+1} \mathrm{~L} J$ terms, giving rise to optical properties. ${ }^{7}$ Similarly, the CF interaction is mandatory to generate the large magnetic anisotropies required for SMMs.

In fact, an isolated $\operatorname{Ln}(\mathrm{III})$ ion only exhibits an isotropic magnetic moment of magnitude $\boldsymbol{g}_{\boldsymbol{j}} \sqrt{\boldsymbol{j}(\boldsymbol{j}+\mathbf{1})} \boldsymbol{\mu}_{\boldsymbol{B}}$ corresponding to the magnetic moments average of the different $M_{J}$ states of the ground tem. Depending on the symmetry and magnitude of the CF, the MJ states are allowed to mix with each other's and the degeneracy of these states is lifted, inducing potential magnetic anisotropy. Therefore, in order to be able to tune the optical, chiroptical and magnetic properties in Ln(III)-based complexes, it is necessary to perfectly characterize and rationalize the CF splitting.

Over the last few years, magneto-luminescence correlations have been used in combination with ab-initio multiconfigurational wavefunction calculations to probe in detail the electronic structure of several $\mathrm{Ln}$ (III)-based SMMs ${ }^{8}$ involving mainly terbium (III), ${ }^{9}$ dysprosium (III), ${ }^{10}$ and ytterbium(III). ${ }^{11}$ In these examples, the luminescence of the $\mathrm{Ln}(\mathrm{III})$ ions was used as a snapshot of the energetic splitting of the ground ${ }^{2 \mathrm{~S}+1} \mathrm{LJ}_{J}$ terms, allowing (i) a direct comparison with the ab-initio electronic structure calculations and (ii) a rationalization of the magnetic properties. The proof of concept was then extended with the use of low-temperature luminescence measurements, allowing an improvement of the spectra's resolution by removing a sizable number of extra transitions corresponding to "hot bands". ${ }^{12}$ However, the assignment of these hot bands is not straightforward and can be easily over-interpreted by the presence of additional effects such as vibronic ones. ${ }^{11 d}$ Despite its wide use, ab-initio calculations might fail as well to provide accurate electronic structure infomation, particularly for strongly correlated systems such as ytterbium-based complexes, where electronic correlation and covalent effects are important and remain challenging to tackle with ab-initio methods.

To circumvent such limitations in the high-resolution characterization of the Ln(III) CF interactions, one step further would be to take advantage of the presence of potential chirality. Indeed, the presence of chiral ligands, or of achiral ligands wrapped around the $\operatorname{Ln}(\mathrm{III})$ ion with a $\Lambda$ - or $\Delta$-helicity, generates enantiomers that interact differently with linearly and circularly polarized light. These enantiomers will absorb or emit photons preferentially with one sense of circular polarization. The presence of additional transition selection rules improves the discrimination of each contribution in the absorption and emission spectra, and in combination with the magnetic and luminescence measurements, it should become possible to determine without ambiguities the electronic structure diagram of the 
investigated Ln(III) complexes. Such an enhanced analysis would ideally require that transitions do not overlap. However, in the general case, the detected signals consist of a sum of individual transitions with identical or opposite signs, which may lead to erroneous interpretations. For instance, a lack of chiroptical signal at a certain energy may be due to opposite components cancelling each other.

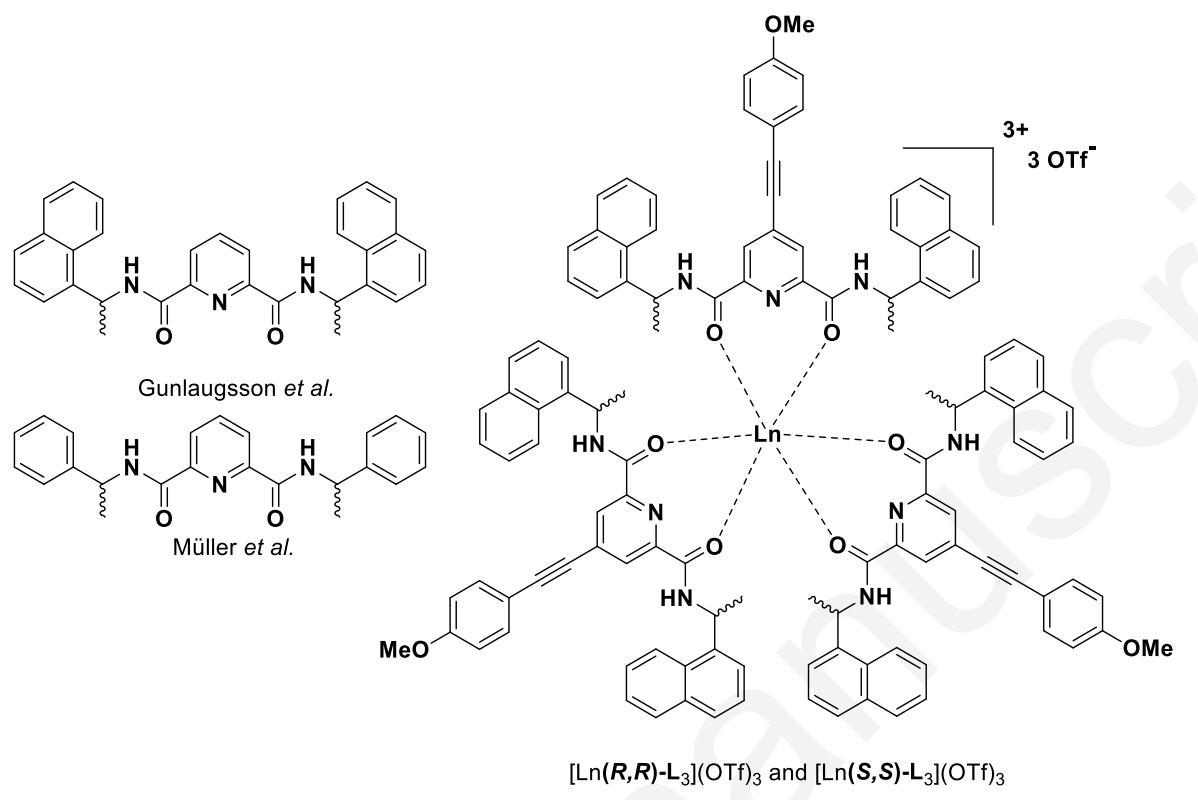

Chart 1. Tridentate ligand leading to the formation of 3-fold symmetric lanthanide complexes featuring an helicoidal chirality. ${ }^{13}$

Herein we present the synthesis, the structural determination, and the spectroscopic characterizations of a helical $\mathrm{Yb}(\mathrm{III})$-based complex containing a charge transfer antenna, functionalized version of an analogous chiral complex developed by Muller and Gunnlaugsson (see Chart 1).13 Our objectives are first to fully characterize the CF splitting of this chiral $\mathrm{Yb}(\mathrm{III})$ complex by combining magnetic measurements in solid state, with room and low-temperature absorption and luminescence measurements. ${ }^{14}$ Secondly, room temperature circular dichroism (CD) and CPL measurements have been carried out using an innovative CPL NIR setup for samples in solution. Hence ab-initio calculations rationalize the electronic structure and the transitions between the CF states and shed light on the current limitation of chiroptical measurements at room temperature.

\section{Synthesis of Ligands and Complexes}

The synthes is of the target ligand consists of the reaction of chelidamic acid (4-hydroxypyridine-2,6-dicarboxylic acid dihydrate) with thionyl chloride to form the transient acid chloride that further reacted with 2,6-bis-N-substituted chiral amide $(R)-(+)$ - or (S)-(-)- 1-(1-naphthyl)ethylamine (see Scheme S1). During this step, the simultaneous aromatic nucleophilic substitution in para-position with a chloro atom was achieved. After replacement of the chloro with a iodo atom using already reported procedure, ${ }^{15}$ the palladium-catalyzed Sonogashira cross-coupling with 4-ethynyl anisole was performed to yield the two enantiopure antennas $(R, R)$ - and $(S, S)$-L, obtained with an overall yield of ca. $50 \%$ for both the enantiomers (Scheme S1, for the detailed procedure see the experimental section and the ESI). The enantiopure complexes are synthesized in a 1:1 mixture of methanol and dichloromethane by adding the lanthanide salt $\left(\mathrm{LnOTf}_{3}, \mathrm{Ln}=\mathrm{Nd}, \mathrm{Pr}, \mathrm{Eu}, \mathrm{Dy}, \mathrm{Tm}, \mathrm{Er}, \mathrm{Yb}\right.$ and $\left.\mathrm{Lu}\right)$ to 3 equivalents of each enantiomer of the ligands $(\boldsymbol{R}, \boldsymbol{R})-\mathrm{L}$ or 
$(\mathbf{S}, \mathbf{S})$-L (Scheme S1): the complexation process is instantaneous, accompanied by a slight color change of the solution from pale to more intense yellow. The pure complexes are isolated by filtration, after a precipitation adding diethyl ether, and fully characterized by ${ }^{1} \mathrm{H},{ }^{13} \mathrm{C}$ NMR and HRMS (see ESI).

\section{Solid-State and Solution Structures}

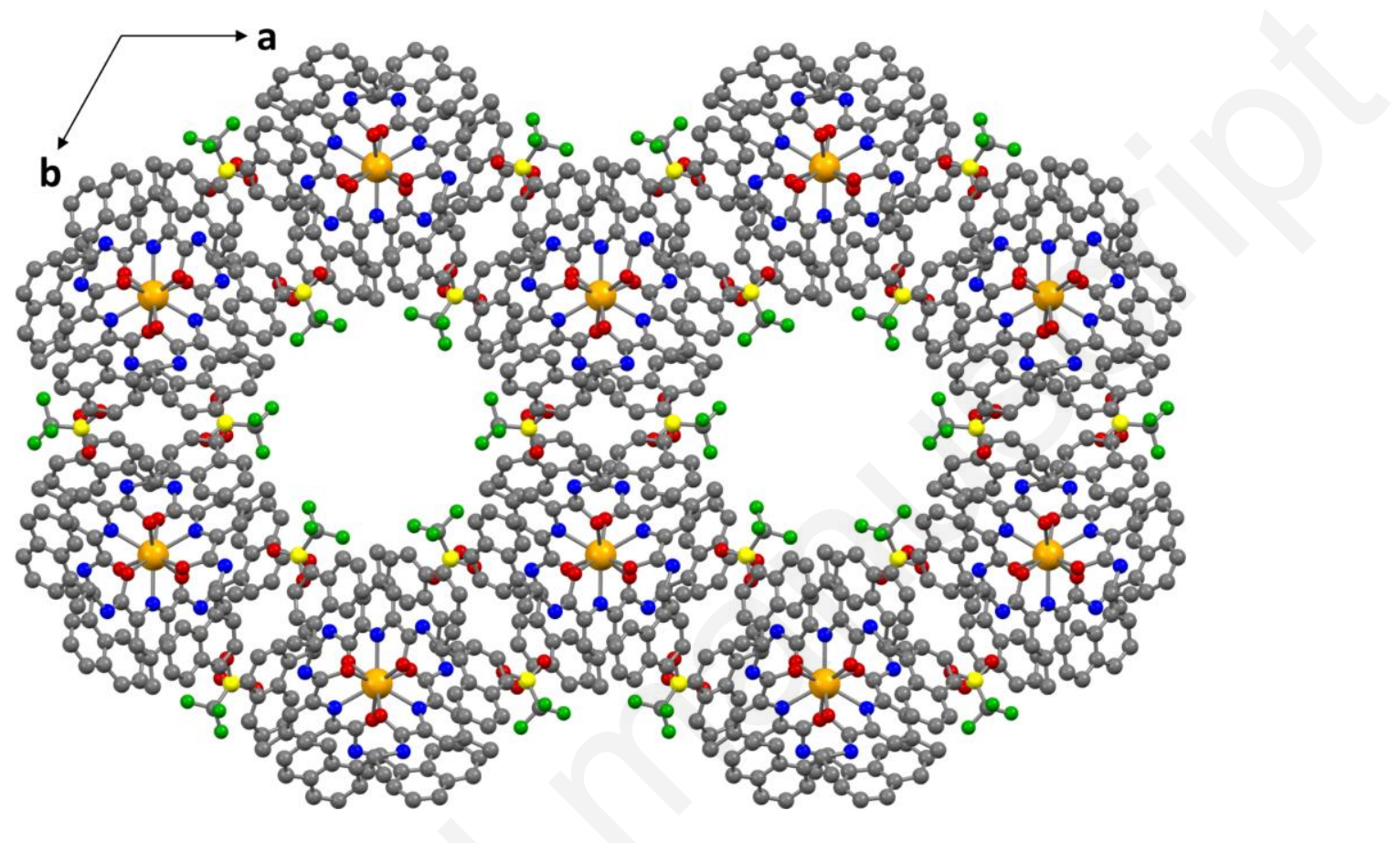

Figure 1. Partial $X$-ray structure of the $\left[\operatorname{Er}(R, R)-\mathrm{L}_{3}\right](\mathrm{OTf})_{3}$ representing the packing as viewed along the $c$ crystallographic axis. The 4-ethynylanisole moiety have not been determined and were replaced by methyl fragments . Protons have been omitted for clarity. Er, O, N, C, F and S atoms are in orange, red, blue, grey, green and yellow, respectively.

Single crystals for X-ray diffraction were grown as yellow needles by slow diffusion of diethyl ether in a methanol solution of the complexes. The best data were collected with crystals of the $\left[\operatorname{Er}(R, R)-L_{3}\right](\mathrm{OTf})_{3}$ complex. Unfortunately, only a partial structure was detemined (see Figure 1), which misses the 4-ethynyl-anisole moiety on each ligand unit. Only the alkyne carbon directly linked to the pyridine ring could be unambiguously located in the electronic density map. However, a comparison can be made with the parent system reported previously by Gunnlaugsson et al. and shown in Figure S1. ${ }^{13 a}$ The three $(R, R)$-L ligands wrap around the lanthanide ion with a $\Lambda$-helicity promoting the $\pi$ interactions in-between each pyridine and naphthalene rings from the two other ligands (Figure S2). Surprisingly, in spite of the presence of the additional $\pi$-extended antennas, the complex crystals are almost isostructural to what previously observed within a $\mathrm{P}_{3}$ chiral space group (Figure S1). An identical hexagonal packing of the complex, promoted by intermolecular $\pi-\pi$ stacking in-between naphthalenes, led to the formation of solvent channels where the ethynyl-anisole moieties stretched (Figure 1). Considering the ca. $8 \AA$ radius of these cavities, a high degree of structural disorder of the antennas is expected, induced both by a possible free rotation of the teminal phenyl rings and steric clash of the three methoxy groups at the center of the channel. 

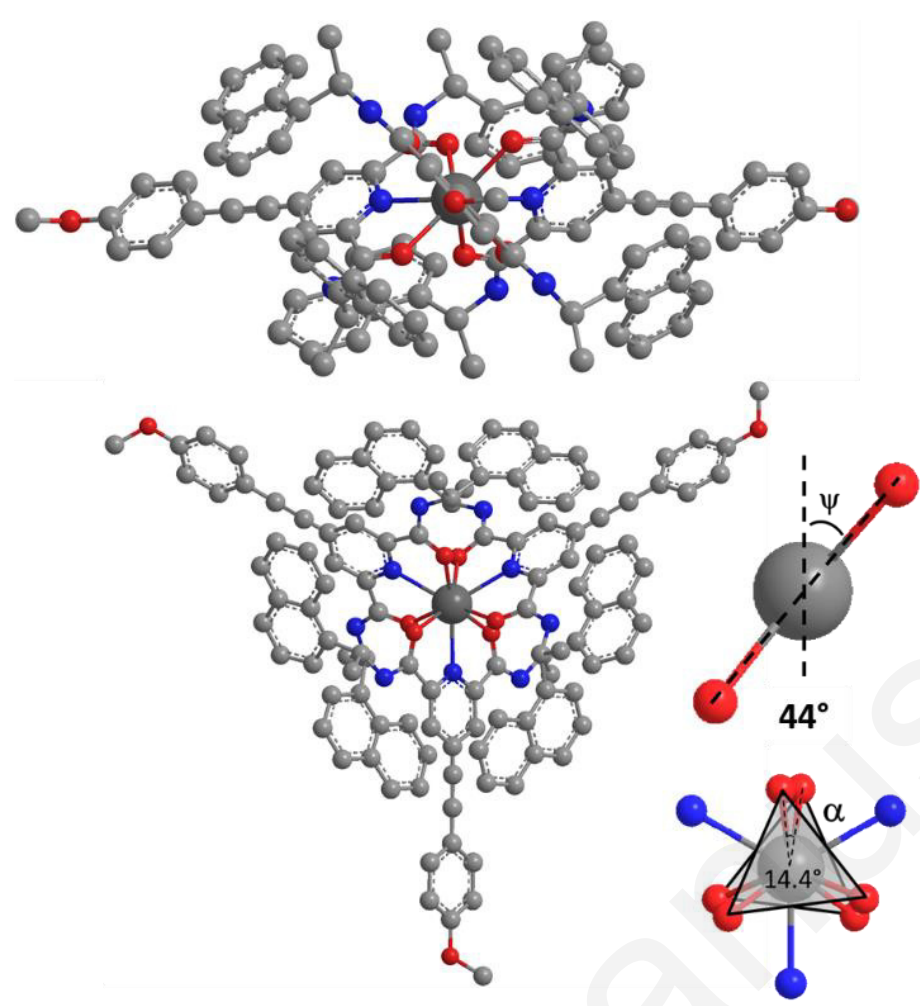

Figure 2. Chem3D model of $\left[\mathrm{Yb}(R, R)-\mathrm{L}_{3}\right]^{3+}$ PERSEUS structure along two views (hydrogen atoms omitted for clarity) with highlighted two important angles characterizing the polyhedron. Color code: $\mathrm{C}$ in gray, $\mathrm{N}$ in blue, $\mathrm{O}$ in red, $\mathrm{Yb}$ in dark gray.

To tackle this drawback, the solution structure of the $\left[\mathrm{Yb}(R, R)-\mathrm{L}_{3}\right](\mathrm{OTf})_{3}$ complex was determined with the PERSEUS (Paramagnetic Enhanced Relaxation and Shift for Eliciting the Ultimate Structure) program ${ }^{16}$ and the resulting structure is given in Figure 2. Such procedure has been successfully applied to determine the solution structures of a large number of Ln-based complexes.$^{17}$ It takes advantage of the high sensitivity of the NMR paramagnetic shifts to the complex geometry. ${ }^{18}$ Indeed, if one assumes that the spin density is localized at the Ln(III) nucleus, the paramagnetic NMR shift of a ligand nuclei $i$ is then dominated by the pseudo-contact term $\left(\delta^{\mathrm{PC}}(i)\right),{ }^{19}$ which is strongly dependent on the relative position of this nuclei with respect to the principal magnetic susceptibility anisotropy axes. Details about the full procedure are given in ESI. As expected, the coordination polyhedron configuration of the solution structure is $\Lambda$ with the $(R, R)$-L enantiomer and its shape is better described as a slightly distorted tricapped trigonal prism: the $\alpha$ angle, which quantifies the distortion from the regular prism, has a value of $14^{\circ}$ with the polyhedron close to be achiral (Figure 2). The skewed angle $\psi$ of the pyridine 2,6-bis-amide plane (which involves also the conjugated anisole moiety) with respect to the $D_{3}$ axis is $44^{\circ}$ and confims the moderate $\delta^{\mathrm{PC}}(i)$ observed. Moreover, the dihedral angles $\mathrm{C} 11-\mathrm{N}-\mathrm{C} 12-\mathrm{C} 13=85^{\circ}$ and $\mathrm{Me}-\mathrm{C} 12-\mathrm{C} 13-\mathrm{C} 21=79^{\circ}$ (see Figure $\mathrm{S} 15$ for the numbering) describe the orientation of the naphtyl rings in space: the rings of one ligand unit are perfectly oriented for a $\pi$ stacking interaction with the pyridine rings of the others (distance around 4-4.5 $\AA$ ). The strength of this interaction is a key point of the stability of the system and it can be interpreted as a case of a multi $\pi$-stacking network between electron rich rings naphtalenes and an electron poor pyridine. Moreover, the ethynyl anisole moiety is perfectly 
coplanar with the 2,6-bis amido pyridine plane. All these structural parameters obtained from the solution structure determination compared well with those obtained byX-ray diffraction (Table S1).

\section{Magnetic Characterizations}

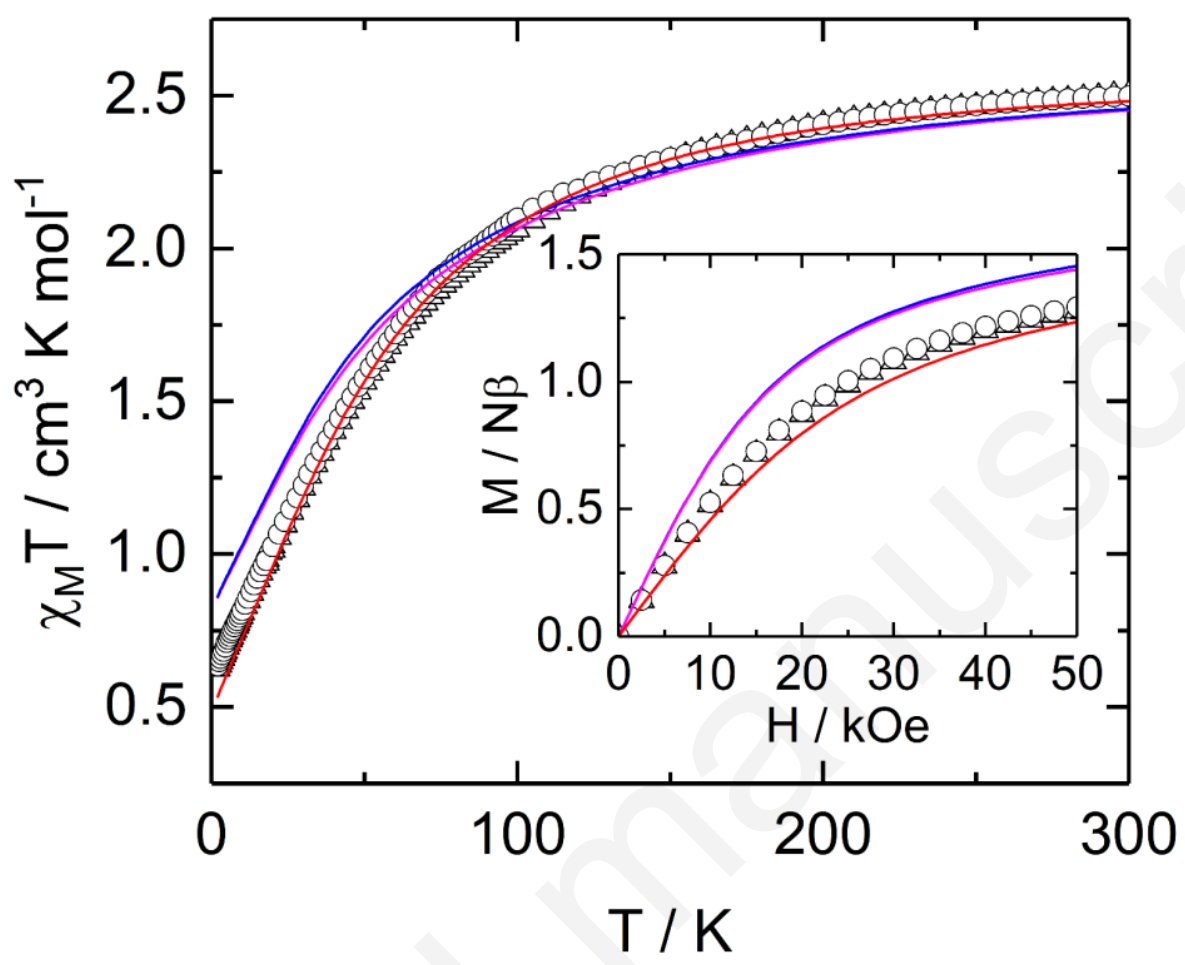

Figure 3. Experimental themal variations of $\mathrm{XMT}_{\mathrm{M}}$ (in $\mathrm{cm}^{3} \mathrm{~K} \mathrm{~mol}^{-1}$ ) for the $\left[\mathrm{Yb}(\boldsymbol{R}, \boldsymbol{R})-\mathrm{L}_{3}\right](\mathrm{OTf})_{3}$ (black circles) and $\left[\mathrm{Yb}(S, S)-\mathrm{L}_{3}\right](\mathrm{OTf})_{3}$ (black triangles) with simulated curves: ab-initio PT2-SO (red line) and crystal field (see text for details) analyses (solution luminescence: magenta, solid state luminescence: blue). Inset: magnetization curves at 2 $\mathrm{K}$ with identical color code.

Magnetic studies were performed on microcrystalline powders of the $\mathrm{Yb}(\mathrm{III})$ derivatives and as expected, the two enantiomers behave similarly since the two $X_{M} T$ vs. T curves are perfectly superimposed (Figure 3). At room temperature, the $X_{M} T$ values $\left(2.5 \mathrm{~cm}^{3} \mathrm{~K} \mathrm{~mol}^{-1}\right)$ agree with the expected value for a ${ }^{2} \mathrm{~F}_{7 / 2}$ multiplet ground state with g $=8 / 7\left(2.57 \mathrm{~cm}^{3} \mathrm{~K} \mathrm{~mol}^{-1}\right)$. On cooling, $\mathrm{XMT}_{\mathrm{M}}$ 's decrease down to $0.63 \mathrm{~cm}^{3} \mathrm{~K} \mathrm{~mol}^{-1}$ due to the splitting of the multiplet ground state. The $\mathrm{M}$ vs $\mathrm{H}$ curves are also perfectly superimposed (inset of Figure 3). Since these two systems do not show any out-of-phase component of the ac susceptibility in zero external dc field, they are not zero field SMM. The example of $\left[\mathrm{Yb}(S, S)-\mathrm{L}_{3}\right](\mathrm{OTf})_{3}$ is given on Figure $\mathrm{S} 3$ and only the data for this compound will be presented here below. The application of a moderate external dc field induces an out-of-phase signal in the frequency window (1-1500 $\mathrm{Hz})$ that does not significantly shift with the applied field but grows in amplitude (Figure S3). One can estimate that the optimum field for which the signal appears at the lowest frequency with the maximum amplitude is close to $1 \mathrm{kOe}$ (Figure S3). At this field, the variation of the ac susceptibility with the oscillation frequency of the magnetic field can be quantitatively analyzed in the framework of the extended Debye model (see Figure 4 and Figure S4). The nonrelaxing fraction of the magnetic susceptibility remains relatively small ( 17-20\%) that means that the vast majority of the magnetic moments are involved in the relaxation process (Table S2). The distribution of the relaxation time 
remains small with a below 0.1 whatever the temperature (Table S2). $\alpha$ close to 1 means an infinite distribution of the relaxation time while $\alpha$ close to 0 means a single relaxation time. The thermal variation of the relaxation time (Figure $5)$ is reproduced with only Raman and direct relaxation processes $\left(\tau^{-1}=C T^{n}+A H^{4} T\right) \cdot{ }^{20}$ The best-fitted curve is obtained with $\mathrm{C}=75.22 \mathrm{~s}^{-1} \mathrm{~K}^{-\mathrm{n}}, \mathrm{n}=5.37, \mathrm{~A}=2.21 \times 10^{-9} \mathrm{~s}^{-1} \mathrm{Oe}^{-4} \mathrm{~K}^{-1}$ (Figure 5). The Orbach process $\left(\tau^{-1}=\tau_{0}^{-1} \exp (\Delta / T)\right)$ that guides the relaxation pathway through Kramers doublets excited states via Arrhenius law, appears to be too slow with reasonable $\tau_{0}$ values and $\Delta=124 \mathrm{~K}$ (ab initio calculations) to interfere with the relaxation process. 


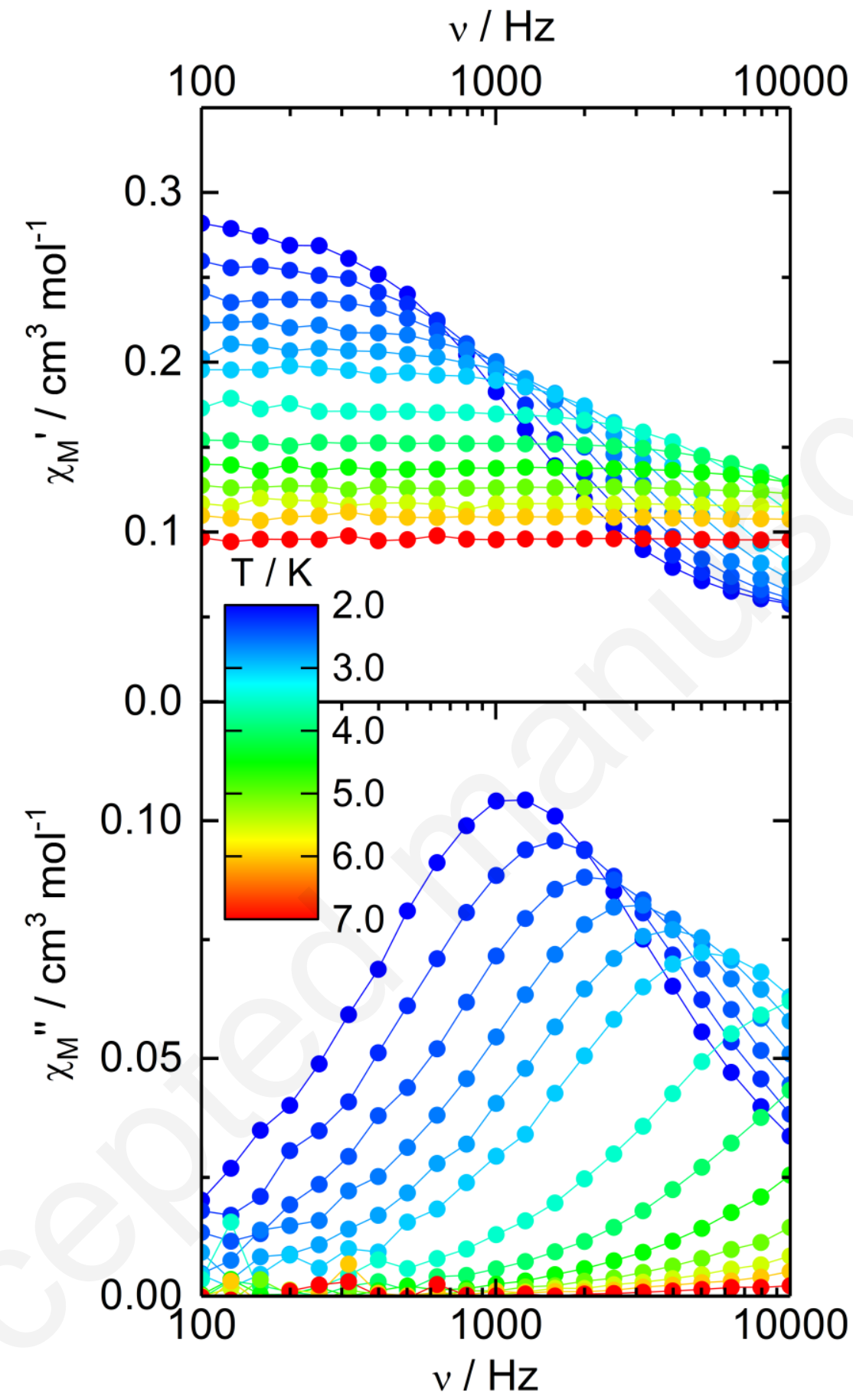

Figure 4. Frequency dependences of the two components, in-phase ( $\mathrm{X}_{\mathrm{m}}^{\prime}$ : top) and out-of-phase ( $\mathrm{X}_{\mathrm{m}}{ }^{\prime \prime}$ : bottom), of the ac magnetic susceptibilitymeasured at $1 \mathrm{kOe}$ as a function of the temperature for $\left[\mathrm{Yb}(S, S)-\mathrm{L}_{3}\right](\mathrm{OTf})_{3}$. 


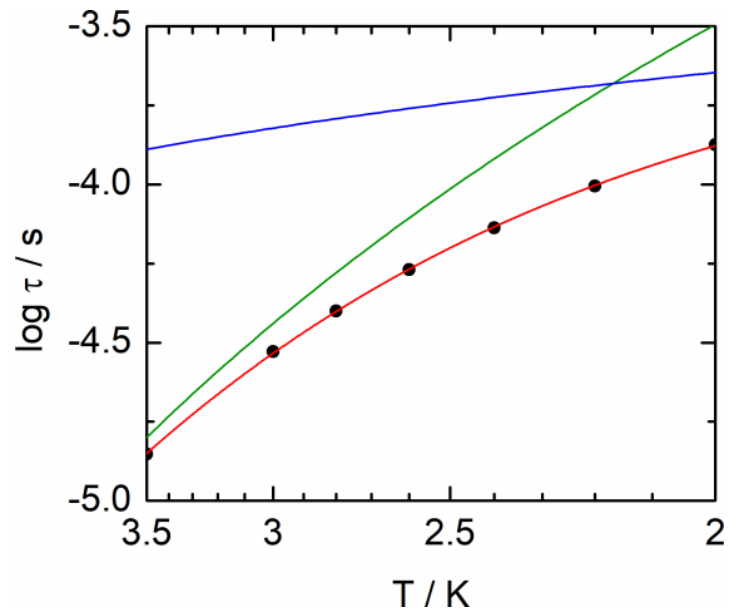

Figure 5. Thermal variation of the relaxation time (black dots) with the best fitted curve in red line and the separated contributions of the Raman (green line) and direct (blue line) processes for $\left[\mathrm{Yb}(S, S)-L_{3}\right](\mathrm{OTf})_{3}$.

\section{Luminescence Characterizations}

Emission. The luminescence has been studied in solution and in the solid state both at room temperature and at 77 $\mathrm{K}$ (Figure 6). Upon excitation at $360 \mathrm{~nm}$ (Figures S5-S6), the classical $\mathrm{Yb}$ (III) emission profile is observed and corresponds to the ${ }^{2} \mathrm{~F}_{5 / 2} \rightarrow{ }^{2} \mathrm{~F}_{7 / 2}$ transition in the NIR. The emission spectra are similar for both enantiomers (Figure S7). Decreasing the temperature down to $77 \mathrm{~K}$ considerably narrowed the emission bands, suppressed the "hot bands" contribution and revealed the crystal field splitting fine structure. In a threefold symmetry, the ${ }^{2} \mathrm{~F}_{7 / 2}$ multiplet ground state splits in four CF states noted $0,1,2,3$ and in three for the ${ }^{2} \mathrm{~F}_{5 / 2}$ excited state noted $0^{\prime}, 1^{\prime}, 2$ '. Erreur! Argument de commutateur inconnu. In the $77 \mathrm{~K}$ solid state spectrum, four signals - three main peaks and one shoulder - can be clearly identified using Gaussian deconvolution (Figure S8, 979.2, 989.8, 998.2, 1013.7 nm) and consequently the energy diagram can be deduced assigning the $979.2 \mathrm{~nm}\left(10213 \mathrm{~cm}^{-1}\right)$ as the zero-line transition (ZLT) $\left(0,109,194,348 \mathrm{~cm}^{-1}\right)$. This simple spectroscopic experimental measurement enables a direct reading of the ${ }^{2} \mathrm{~F}_{7 / 2}$ ground state CF. In frozen solution, the similar structure induces a comparable energy diagram obtained from the luminescence spectrum (Figures 6 and S8, 0, 107, 201, $355 \mathrm{~cm}^{-1}$ ). Note that the experimental error for such measurements is in the nanometer range and corresponds to a precision in the energy splitting determination estimated to $+/-10 \mathrm{~cm}^{-1}$. The two CF splittings obtained in frozen solution and in the solid state at $77 \mathrm{~K}$ are almost identical, indicating that the coordination sphere remains the same in both cases. It is well known that the total CF splitting is a signature of the local symmetry of the $\mathrm{Yb}(\mathrm{III})$ coordination polyhedron. ${ }^{21}$ In the present case, the total splitting noted $\Delta_{C F}$ is small, about $348 \mathrm{~cm}^{-1}$ in the solid state $\left(355 \mathrm{~cm}^{-1}\right.$ in frozen solution). This value is perfectly in line with that previously determined in the literature for three-fold complexes like tris-dipicolinate $\left(\Delta \mathrm{cF}=348 \mathrm{~cm}{ }^{-1}\right)$, ${ }^{22}$ helicates $\left(\Delta_{\mathrm{CF}}=372 \mathrm{~cm}^{-1}\right),{ }^{23}$ or murex complexes $\left(\Delta_{\mathrm{CF}}=366 \mathrm{~cm}^{-1}\right)$ Erreur ! Argument de commutateur inconnu. ${ }^{\mathrm{b}}$ and much lower than that of $C_{2 v}\left(\Delta_{\mathrm{CF}}=670 \mathrm{~cm}^{-1}\right)^{24}$ or even lower symmetry complexes $\left(\Delta_{\mathrm{CF}}\right.$ up to $\left.880 \mathrm{~cm}^{-1}\right) \cdot{ }^{25} \mathrm{Finally}$, the luminescence lifetime for the two enantiomers of the $\mathrm{Yb}$ (III) complex has been measured (Figure S9) and fitted with a perfect mono-exponential decay giving $\tau=6.1-6.2 \mu \mathrm{s}$, in the classical range for non-deuterated $\mathrm{Yb}(\mathrm{III})$ complexes in organic solution. ${ }^{11 b, 11 f, 22,24,25}$ 

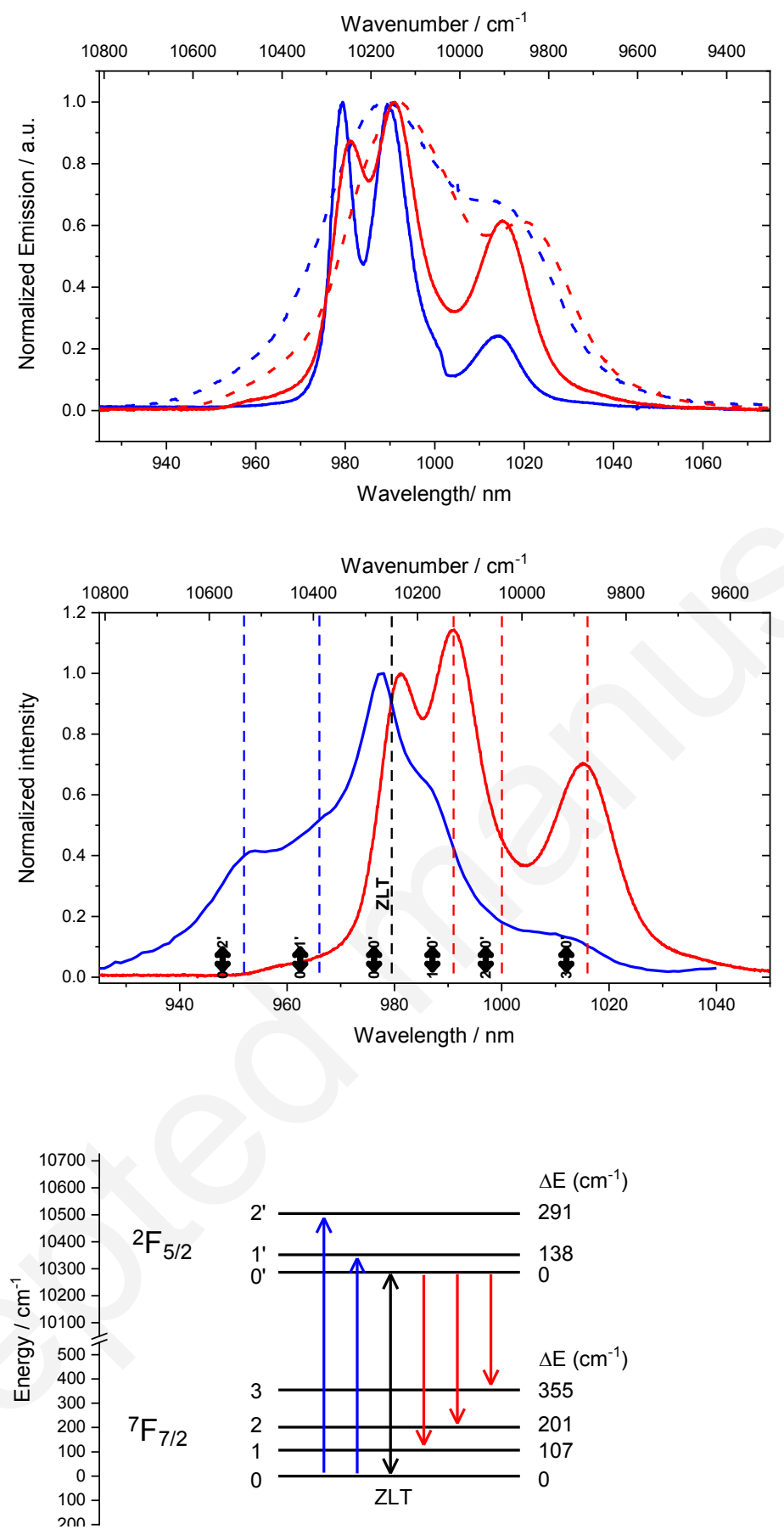

Figure 6. (top) Luminescence spectra of $\left[\mathrm{Yb}(\mathrm{S}, \mathrm{S})-\mathrm{L}_{3}\right](\mathrm{OTf})_{3}$ in solution of ethanol : methanol $=4: 1$ at 298 (red dashed) and at $77 \mathrm{~K}$ (red solid); in solid state at 298 (blue dashed) and $77 \mathrm{~K}$ (blue solid). (Middle) Nomalized absorption (blue) and emission (red) spectra at $298 \mathrm{~K}$ in methanol. (Bottom) Experimental energy diagram with related transitions.

Absorption. The NIR-absorption spectrum was measured only in solution and at room temperature. It spreads between 950 and $1050 \mathrm{~nm}$ and presents a rather poor resolution. Overlay with the emission spectrum (Figure 6) 
confims the ZLT position at $979.2 \mathrm{~nm}$ in the absorption, as well. At room temperature, the maximum in absorption is blue-shifted by $3 \mathrm{~nm}$ compared to the ZLT. Five main structures can be observed. The short-wave part of the spectrum corresponds to the $0 \rightarrow$ i' (i' = 1', 2') transitions (shoulders at 952 and $966 \mathrm{~nm}$ ) while the long wavelength side can be assigned to the transitions from themally occupied ground state levels (i.e. hot bands in absorption). These three hot absorption bands $(991,1000$ and $1016 \mathrm{~nm})$ match well the emission spectrum. From this assignment, the CF splitting of the ${ }^{2} \mathrm{~F}_{5 / 2}$ excited state can be deduced as $0,138,291 \mathrm{~cm}^{-1}$.

Boltzmann distribution. The ${ }^{2} \mathrm{~F}_{5 / 2}$ and ${ }^{2} \mathrm{~F}_{7 / 2} \mathrm{CF}$ splitting determined above reveals that the multiplet extension ( 300 $\left.\mathrm{cm}^{-1}\right)$ is in the same order of magnitude as $\mathrm{kT}$ at room temperature $\left(208 \mathrm{~cm}^{-1}\right.$ at $\left.300 \mathrm{~K}\right)$. This population distribution leads to an overall broadening of the achiral optical features. We have then computed the variation of the Boltzmann's distribution with the temperature using a three and four levels Boltzmann model (see SI for complete calculation, Figure S10). It must be mentioned that all CF states are Kramers doublets and are then all doubly degenerated. A relative distribution of 57, 29 and 14\% for the 0,, 1', 2' CF states, respectively, is clearly determined for the ${ }^{2} \mathrm{~F}_{5 / 2}$ excited state at room temperature. Population of the ground state multiplet is distributed as $46,28,18$ and $8 \%$ for the $0,1,2,3 \mathrm{CF}$ states. These values clearly show that all the multiplets are populated and, consequently, all the $\mathrm{i} \leftrightarrow \mathrm{j}$ transitions can have an impacton the spectra.

\section{Chiroptical Characterizations}

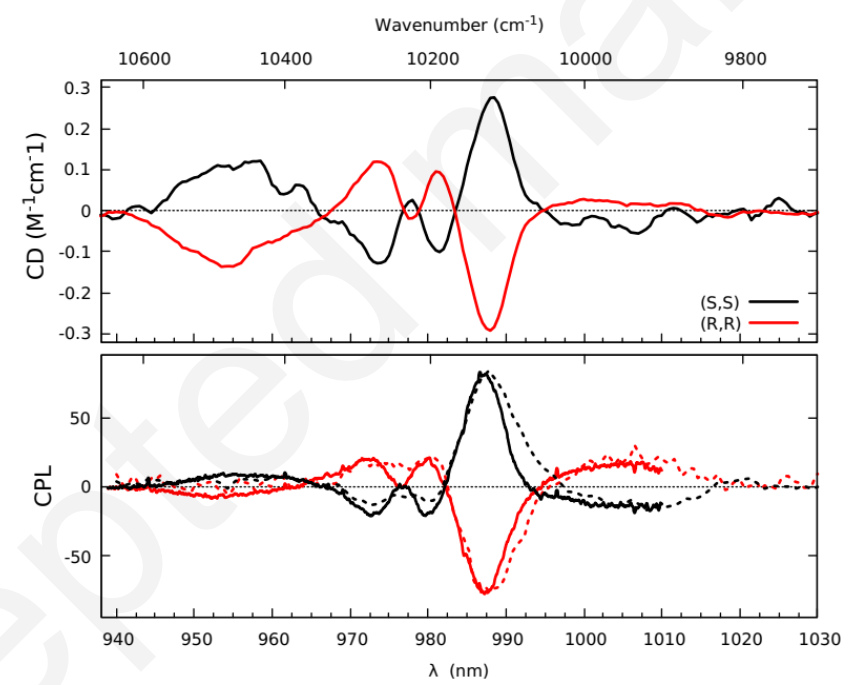

Figure 7. NIR-ECD (top) and NIR-CPL (bottom) spectra of $\left[\mathrm{Yb}(\boldsymbol{R}, \boldsymbol{R})-\mathrm{L}_{3}\right](\mathrm{OTf})_{3}$ (red) and $\left[\mathrm{Yb}(\boldsymbol{S}, \boldsymbol{S})-\mathrm{L}_{3}\right](\mathrm{OTf})_{3}(\mathrm{black})$ complexes in methanol solution at $298 \mathrm{~K}$. For the NIR-CPL, two set-ups were used either with a CCD Si camera (continuous line) or an IR photomultiplier (dotted lines) as detectors.

The chiroptical super-spectrum ${ }^{26}$ of the $\left[\mathrm{YbL}_{3}\right](\mathrm{OTf})_{3}$ complex, combining various chiroptical spectroscopies in different spectral range, visible electronic circular dichroism (ECD), NIR-ECD, circularly polarized luminescence (NIRCPL) and vibrational circular dichroism (VCD) was determined for the first time for an ytterbium derivative (Figure 7 and Figures S11-S12). The NIR-ECD and NIR-CPL spectra of the two enantiomers of [YbL 3 ] $\left(\mathrm{OTf}_{3}\right)_{3}$ were recorded in concentrated methanol solution ( $4 \mathrm{mM}$ ) with our home-made apparatus (see Supporting Information). For the CPL, we have used two set-ups: one is based on a CCD camera and waveplates similar to what is used for chiral contrast imaging. ${ }^{27}$ It allows recording one-shot high-resolution spectra but is limited by the sensitivity of the Si sensors. ${ }^{28}$ The 
other one that uses a standard photoelastic modulator and a single channel detector, is less resolved but can be used down to $1500 \mathrm{~nm} .{ }^{29}$ It is worth noting that NIR-chiroptical measurements are relatively rare ${ }^{30}$ compared to visible ones that are widely exemplified for europium(III), terbium(III) and samarium(III) chiral complexes. Erreur ! Argument de commutateur inconnu. 29

NIR-ECD and CPL spectra for the ${ }^{2} \mathrm{~F}_{7 / 2} \leftrightarrow{ }^{2} \mathrm{~F}_{5 / 2}$ transition of the $\left[\mathrm{Yb}_{3}\right](\mathrm{OTf})_{3}$ complexes are displayed in Figure 7 . Erreur! Signet non défini. This transition is magnetically allowed, highly sensitive to the $\mathrm{Yb}(\mathrm{III})$ ion environment and therefore particularly suited for chiroptical spectroscopy. At room temperature, the ECD and CPL spectra are much more structured than the absorption and emission ones. They are comparable in terms of energetic position and are mirror images for the two enantiomers. The strongest band appears in both ECD and CPL at around $987 \mathrm{~nm}(\mathrm{FWHM}=5 \mathrm{~nm})$. This band is positive for the $(S, S)$ enantiomer with significant absorption and emission dissymmetry factors $g=+0.04$ and $g_{\text {lum }}=+0.11$. On the low energy side of this band, a broad CPL signal of opposite sign extends from 994 to $1016 \mathrm{~nm}$. The corresponding ECD signal is hardly observable as expected for a hot band in absorption. At shorter wavelengths, we clearly count three bands in CPL at 980 (negative), 973 (negative) and 954 $\mathrm{nm}$ (positive) about 4 times lower in intensity. This last transition is much broader (FWHM $=20 \mathrm{~nm}$ ) than the other two (around $5 \mathrm{~nm}$ ). The ECD spectra get the same overall shape but the short wavelength intensities are stronger and a small peak of opposite sign appears between the two peaks at 973 and $980 \mathrm{~nm}$. The different features observed at room temperature do not match with the energies of the CF states determined from absorption and emission spectroscopies (vide supra). This apparent inconsistency has been investigated under the light of ab-initio calculations (Figure 9). The short wavelength band (around $950 \mathrm{~nm}$ ) is calculated as a 2' $\leftrightarrow 0$ transition which also explains the fact that it is more intense in ECD than CPL. This negative band is followed at higher wavelengths by a complicated structure mixing three positive bands involving 0', 1' and 2' states as well as the negative contribution from the 1 ' $\leftrightarrow 1$ transition. The exact position, as well as the relative intensities of these bands can lead to the experimental shape observed in the $965-980 \mathrm{~nm}$ spectral range (Figure 9). The strong band at $988 \mathrm{~nm}$ is the sum of the $1 ' \leftrightarrow 2,2$ ' $\leftrightarrow 3$ and 0 ' $\leftrightarrow 1$ transitions. Its intensity will depend strongly on the temperature of measurement as a consequence of the thermal population of the different ${ }^{2} \mathrm{~F}_{5 / 2}$ sublevels. The long wavelength $\mathrm{CPL}$ signal is related to the 1 ' $\leftrightarrow 3$ transition, it is thus a hot band in absorption leading to a low ECD signal. Based on all these interpretations, it clearly appears that the apparently well-resolved ECD and CPL spectra at room temperature are in fact the combination of all CF states and consequently the experimental determination of the energy diagram from room temperature chiroptical data remains hardlypossible.

\section{Ab-initio Calculations}

In order to gain further insight into the optical and magnetic properties of the $\left[\mathrm{Yb}(\boldsymbol{R}, \boldsymbol{R})-\mathrm{L}_{3}\right](\mathrm{OTf})_{3}$ complex, multireference calculations were performed at the SCF/PT2-SO level on a model compound [YbL' 3$]^{3+}$ resulting from the solution structure determined by NMR (see computational details). The nature of the ground state (GS) was first characterized with the help of the natural spin orbitals (NSOs) as shown in Figure 8. These NSOs represent the distribution of the unpaired electron among the $4 \mathrm{f}$ spin-orbitals. ${ }^{31}$ The largest positive spin-populations (i.e. spin-up) are calculated for the NSOs $4 f_{x y z}\left(0.40 e^{-}\right)$and $4 f_{z\left(x^{2}-y^{2}\right)}\left(0.31 e^{-}\right)$which are associated to a projected orbital angular momentum $m_{l}= \pm 2$. Additionally, a sizable negative spin-population $\left(-0.22 e^{-}\right)$is calculated for the $N S O 4 f_{x}\left(x^{2}-3 y^{2}\right)$ corresponding to a $m_{l}= \pm 3$. The sum of these spin-populations gives a spin expectation value $\left\langle S_{\|}\right\rangle=0.21$, revealing the importance of the SO coupling in the nature of the GS. Using the total angular momentum $\mathrm{J}$ and its projections $\mathrm{M}_{\mathrm{J}}$, 
the distribution of the unpaired electron derives formally from the Kramers doublet $\mid 7 / 2, \pm 5 / 2>$ of the ${ }^{2} F_{7 / 2}$ multiplet. For reference, the composition of this $M_{J}$ state for a $4 f^{13}$ free ion in term of $m_{\text {। }}$ and $m_{s}$ would be of ca. $86 \% \mid \pm 2, \pm 1 / 2>$ and $14 \% \mid \pm 3, \pm 1 / 2>$. However, the almost trigonal environment around the $\mathrm{Yb}(\mathrm{III})$ ion in $\left[\mathrm{YbL}_{3}\right]^{3+}$ leads to a mixing of the $M_{J}= \pm 5 / 2$ with the $M_{\jmath}= \pm 1 / 2$ and $\pm 7 / 2$. As seen in Figure 8 , the small deviation from a perfectly trigonal environment creates a symmetry breaking in the wave function that is visible with the sizable mixing with the $M_{J}=-$ $3 / 2$ state. This mixing of the different $M_{J}$ states into the SO wave function is responsible for the small magnetic anis otropy of the GS, characterized by the two large perpendicular components of the $g$-factors and a relatively small parallel component $\left(g_{\|}=3.38\right)$. The calculated isotropic magnetization is found in really good agreement with the experimental one at very low $T$, suggesting a proper description of the nature of the GS (Figure 3). Additionally, for the temperature-dependence of $\chi_{M} T$ a nice agreement with the experiment is obtained at the PT2-SO level. This behavior corresponds to the thermal population of the excited $\mathrm{M}_{\mathrm{J}}$ states of ${ }^{2} \mathrm{~F}_{7 / 2}$ that are calculated at 86,138 and 290 $\mathrm{cm}^{-1}$ above the GS, respectively.

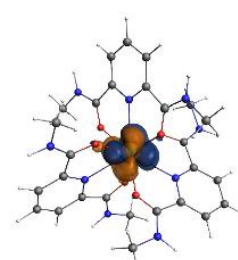

0.40

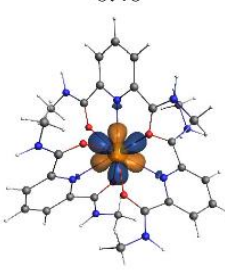

$-0.22$

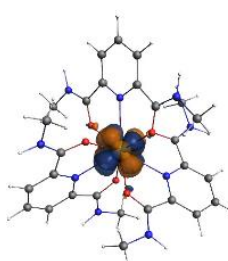

0.31

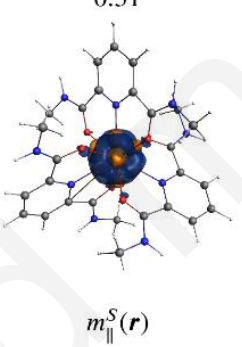

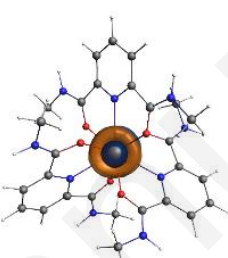

$-0.06$

$\left\langle L_{\|}\right\rangle=1.26$

$\left\langle S_{\|}\right\rangle=0.21$

$g_{\|}=3.38$

$g_{\perp}=1.93 / 0.57$

$\psi_{\mathrm{GS}}=63\left|7 / 2, \pm^{5} / 2\right\rangle+$

$\left.8\left|7 / 2, \mp^{1 / 2}\right\rangle+\left.11\right|^{7} / 2, \mp^{3} / 2\right\rangle$

$+17\left|7 / 2, \mp^{7} / 2\right\rangle$

Figure 8. Selected Natural Spin Orbitals (NSOs) (isosurface values $= \pm 0.03$ a.u.) and their corresponding spin populations for the Kramers doublet GS obtained at the PT2-SO level. The isosurface ( \pm 0.001 a.u.) of the spinmagnetization $\left(m_{\|} \mathrm{s}(r)\right)$ for the doublet component $\left\langle S_{\|}>>0\right.$ is also shown. The orbital and spin expectation values, the EPR g-factors and the nature of the wave function calculated for the GS are given for comparison. Additional data are presented in Tables S3 and S4 of the Supporting Information.

The calculated CPL spectrum is shown in Figure 9. Here, the calculations were performed at the RASPT2 level in order to mix the $4 f^{13}$ configurations with the $4 f^{12} 5 d^{1}$ ones. This mixing of configurations allows gaining electric dipole intensities for the $4 \mathrm{f}-4 \mathrm{f}$ transitions by breaking the parity rule. ${ }^{32}$ Such a procedure was successfully applied recently to obtained the CPL spectrum of an analogous Eu(III) tris-dipicolinate complex. ${ }^{33}$ At $0 \mathrm{~K}$, the calculated CPL spectrum exhibits a strong positive and a strong negative band corresponding to the $0^{\prime} \rightarrow 0$ and $0^{\prime} \rightarrow 1$ transitions, respectively. The increase of the temperature leads to the appearance of a second positive band corresponding to the 1 ' $\rightarrow 0$ transition, as observed experimentally. However, the comparison with the experimental spectrum suggests that the excited state $1^{\prime}$ is calculated too low in energy as the intensity of this hot band becomes too important at room temperature. Interestingly, the breakdown of the calculated CPL spectrum into the different contributions from the three excited states of ' $\mathrm{F}_{5 / 2}$ (Figure 9) reveals that the principal negative CPL band does not only correspond to the 0 ' $\rightarrow 1$ transition as suggested experimentally, butalso contains contributions from the 1 ' $\rightarrow 2$ and 2 ' $\rightarrow 3$ transitions 

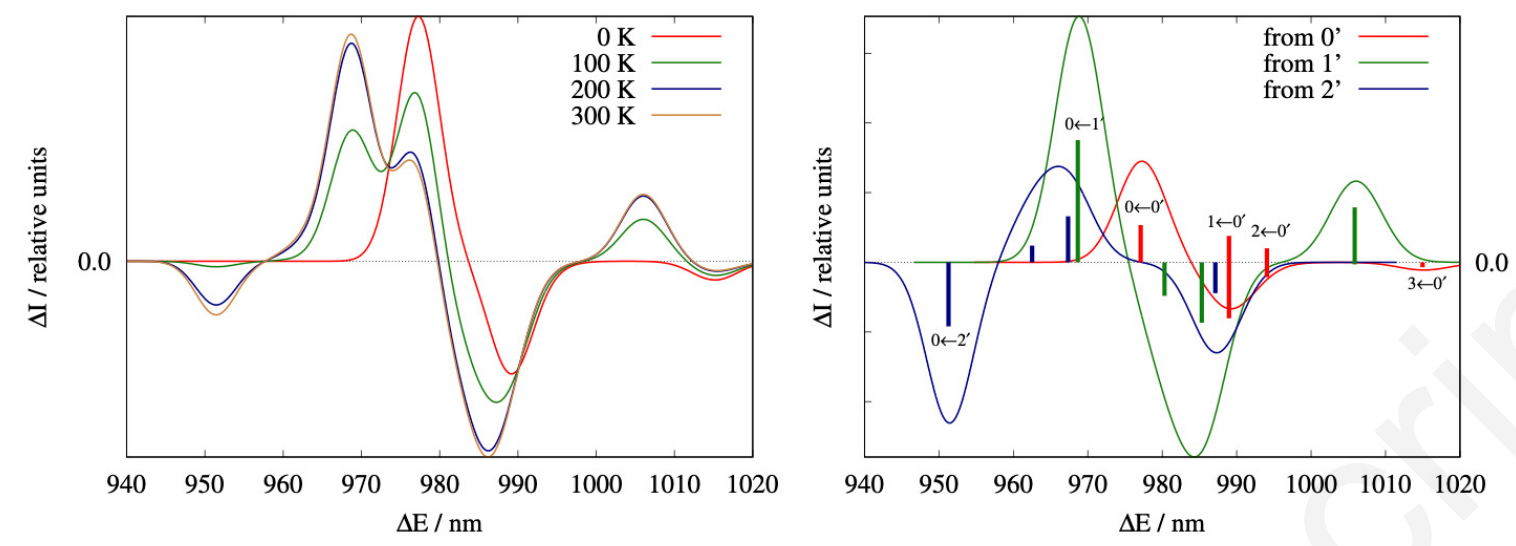

Figure 9. Calculated CPL spectrum of $\left[\mathrm{Yb}(R, R)-\mathrm{L}^{\prime}\right]^{3+}$ as a function of the temperature (left) and the different contribution at $300 \mathrm{~K}$ from the ${ }^{2} \mathrm{~F}_{5 / 2}$ term. Calculated spectra have been shifted by $0.07 \mathrm{eV}$ to match the experimental 0 ' $\rightarrow 0$ transition. Calculated raw data are given in Table S5.

\section{Crystal-field analysis}

Based on the luminescence characterizations of the $\left[\mathrm{YbL}_{3}\right](\mathrm{OTf})_{3}$ complex, it is then possible to establish its electronic structure and hence, detemine the CF parameters. At first, one can assume that the $\mathrm{Yb}$ (III) ion is located in a trigonal environment ( $D_{3}$ symmetry), and express the CF Hamiltonian as:

$$
\widehat{H}^{C F}=\alpha_{\mathrm{J}}\left[\mathbf{B}_{2}^{0} \widetilde{\mathbf{0}}_{2}^{0}(J)\right]+\beta_{\mathrm{J}}\left[\mathbf{B}_{4}^{0} \widetilde{\mathbf{0}}_{4}^{0}(J)+\mathbf{B}_{4}^{3} \widetilde{\mathbf{0}}_{4}^{3}\right]+\gamma_{\mathrm{J}}\left[\mathbf{B}_{6}^{0} \widetilde{\mathbf{0}}_{6}^{0}(J)+\mathbf{B}_{6}^{3} \widetilde{\mathbf{0}}_{6}^{3}(J)+\mathbf{B}_{6}^{6} \widetilde{\mathbf{0}}_{6}^{6}(J)\right] \quad(E q 1 .)
$$

where the $\alpha_{\mathrm{J}}, \beta_{\mathrm{J}}$ and $\gamma_{\mathrm{J}}$ are parameters obtained using the Wigner-Eckart theorem and depend on the considered $\mathrm{J}$ manifold (here $\mathbf{J}=7 / 2$ ), the $\widetilde{\mathbf{O}}_{\mathbf{k}}^{\mathbf{q}}(J)$ are the Stevens operators, and the $\mathbf{B}_{\mathbf{k}}^{\mathbf{q}}$ terms are the CF parameters. Since the ground term ${ }^{2} F_{7 / 2}$ is well separated from the excited one (over $10,000 \mathrm{~cm}^{-1}$ ), the matrix elements $\left\langle\mathbf{J}, \mathbf{M}_{\mathbf{J}}\left|\widetilde{\mathbf{0}}_{\mathbf{k}}^{\mathbf{q}}\right| \mathbf{J}, \mathbf{M}_{\mathbf{J}}^{\prime}\right\rangle$ can be simply determined by using the values originally tabulated by Stevens. ${ }^{20}$ In this work, the $\mathbf{B}_{2}^{0}$ term in Eq. 1 was determined by performing luminescence measurement on the Eu(III) analogue complex and by measuring the energetic splitting of the ${ }^{7} F_{1}$ multiplet (see Figure S13) ${ }^{34}$ Indeed, in a trigonal CF the splitting corres ponds to 3 times the term $\mathbf{B}_{2}^{\mathbf{0}}$; the sign being determined by the ordering of the degenerate vs non-degenerate components of the multiplet. The analys is of the emission spectrum in solution leads to $\mathrm{J}=1$ transition CF splitting of $90 \mathrm{~cm}^{-1}$, and hence to a $\mathbf{B}_{2}^{\mathbf{0}}$ term equal to ca. $-30 \mathrm{~cm}^{-1}$. The value of $\mathbf{B}_{2}^{\mathbf{0}}$ for the $\mathrm{Yb}$ (III) analogue differs probably from the Eu(III) case. However, theoretical investigations have shown that for a given series and ass uming small geometrical relaxations, ${ }^{35}$ the $\mathbf{B}_{\mathbf{2}}^{\mathbf{0}}$ remains almost constant along the series, and therefore $\mathbf{B}_{\mathbf{2}}^{\mathbf{0}}$ was kept fixed at $-30 \mathrm{~cm}^{-1}$. The rest of the $\mathbf{B}_{\mathbf{k}}^{\mathbf{q}}$ terms were then obtained with least-squares procedures by fitting the energies obtained from luminescence measurements carried out on the investigated complex. The results of each set of CF parameters are given in Table 1 along with the nature of the associated GS. To assess the quality of the fits, the CF parameters were then used to simulate the magnetic properties ( $\chi_{M} \top$ product and magnetization) and compared to the experimental data (see Figure 3). 
As visible in Table 1, the magnitude of CF parameters remains relatively close between the different luminescence measurements. The fact that the $\mathbf{B}_{\mathbf{2}}^{\mathbf{0}}, \mathbf{B}_{\mathbf{4}}^{\mathbf{0}}$ and $\mathbf{B}_{\mathbf{6}}^{\mathbf{0}}$ terms are of the same order of magnitude and all negative leads to a GS that is mainly of $M_{J}= \pm 5 / 2$ character. These small differences in the CF parameters hardly affect $\chi_{M} T$ (see Figure 3 ), which converges to the experimental data at room temperature. However, at low-temperature the experimental $\chi_{M} T$ is overestimated by the CF analyses, suggesting a too large magnetic moment for the GS. This result is confirmed with the over-estimation of the magnetization at $2 \mathrm{~K}$ (see Figure 3 ). The difference at low temperature between the CF analyses and the experimental data can be rationalized with the help of the ab-initio calculations. As mentioned previously, the $\left[\mathrm{Yb}(\boldsymbol{R}, \boldsymbol{R})-\mathrm{L}_{3}\right](\mathrm{OTf})_{3}$ complex is not perfectly trigonal but corresponds to a slightly distorted tricapped trigonal prism (see Figure 2). The lowering of symmetry induces a larger mixing in the GS wavefunction with other MJ states (see Figure 8), which reduces the magnetic moment of the GS. Such an admixture of states cannot be reproduced by a strict trigonal CF. As visible with the calculated ab-initio CF parameters (Table S5), a larger number of CF parameters is considered in order to get the proper wavefunction. It results in a great reproduction of the magnetic susceptibilityand magnetization curves (Figure 3).

Table 1. Experimental and calculated energy splitting (in $\mathrm{cm}^{-1}$ ) of the ground multiplet ${ }^{2} \mathrm{~F}_{7 / 2}$ in $\left[\mathrm{Yb}(\boldsymbol{R}, \boldsymbol{R})-\mathrm{L}_{3}\right](\mathrm{OTf})_{3}$. The CF parameters $\left(\mathbf{B}_{\mathbf{k}}^{\mathbf{q}}\right.$, in $\left.\mathrm{cm}^{-1}\right)$ deduced from these relative energies and the composition of the GS wavefunction are also given for comparison.

\begin{tabular}{cccc}
\hline & $\begin{array}{c}\text { Lum Sol. } \\
(77 \mathrm{~K})\end{array}$ & $\begin{array}{c}\text { Lum Solid } \\
(77 \mathrm{~K})\end{array}$ & $\begin{array}{c}\text { Ab-initio* } \\
\text { Sol. }\end{array}$ \\
\hline${ }^{4} \mathrm{~F}_{7 / 2}$ & 0 & 0 & 0 \\
& 107 & 109 & 86 \\
& 201 & 194 & 138 \\
& 355 & 348 & 290 \\
$\mathrm{~B}_{2}^{0}$ & -30 & -30 & -24 \\
$\mathrm{~B}_{4}^{0}$ & -98 & -91 & -47 \\
$\mathrm{~B}_{4}^{3}$ & -85 & -173 & -80 \\
$\mathrm{~B}_{6}^{0}$ & -22 & -20 & -11 \\
$\mathrm{~B}_{6}^{3}$ & 1178 & 1183 & -29 \\
$\mathrm{~B}_{6}^{6}$ & 262 & 289 & -56 \\
$\% \mathrm{M}_{J}= \pm 1 / 2$ & 13 & 14 & 8 \\
$\% \mathrm{M}_{J}= \pm 3 / 2$ & 0 & 0 & 11 \\
$\% \mathrm{M}_{J}= \pm 5 / 2$ & 78 & 75 & 63 \\
$\% \mathrm{M}_{J}= \pm 7 / 2$ & 8 & 11 & 17 \\
\hline${ }^{*}$ the additional ab-initio CF parameters are given in Table S6.
\end{tabular}

Advanced theoretical calculations revealed that chiroptics cannot be analyzed in the same way (vide supra). In normal absorption or emission measurements if two different transitions fall at the same wavelength intensities of the transitions gets added: there is no negative absorption or emission. In CD and CPL the signal of each transition at this wavelength can be either positive or negative. The resulting measured signal being the sum it can be positive, negative or even null depending on the respective amplitudes. In other words, the non-observation of a signal does not automatically mean that there are no transitions. It thus makes the analysis of room temperature experiments hazardous especially for lanthanide based complexes in which the crystal field splitting is small and emission lines 
close to each other's inside the same multiplet, like in [YbL 3 (OTf $)_{3}$ system. Indeed, the CPL spectrum is temperature dependent with great modulations and shift of the various lines (as demonstrated with calculations; Figure 9). If one wants chiroptical information to be a source of CFS information one needs low temperature CPL measurements, a task that still needs to be achieved. ${ }^{36}$

\section{Conclusions}

The electronic structure of the chiral $\left[\mathrm{YbL}_{3}\right](\mathrm{OTf})_{3}$ complex has been characterized with the help of a combination of magnetic, absorption and luminescence characterizations carried out at low and room temperature in solution and in solid-state. From these spectroscopies, we have been able to determine the energetic splitting of the ground ${ }^{2} F_{7 / 2}$ and excited ${ }^{2} \mathrm{~F}_{5 / 2}$ terms arising from the crystal-field splitting. The temperature resolved luminescence spectroscopy produced similar electronic structures that with the ab-initio calculations. The CF picture was then achieved by assuming a perfect trigonal environment ( $D_{3}$ symmetry) that allows reproducing qualitatively temperature variation of the magnetic susceptibility. However, this CF picture was not able to reproduce the proper magnetic moment of ground state because the $\left[\mathrm{YbL}_{3}\right](\mathrm{OTf})_{3}$ complexexhibits a slight deviation from the ideal $D_{3}$ symmetry.

NIR chiroptical measurements (ECD and CPL) at room temperature revealed features that can only be rationalized on the basis of advanced theoretical calculations since the superposition of various transitions at almost the same wavelength in lanthanide-based complexes truncates the analysis in the Boltzmann landscape. This makes the extraction of CF transitions impossible at room temperature. The quantitative description of chiroptical properties thus waits for low-temperature measurements. In this line, glum values that are considered in the literature as intrinsic observables of each emission line may be experimentally the result of a sum of various contributions and might not be considered definite. In following works, we will combine thus variable-temperature magneto-lumino-chiroptical techniques on a wider range of symmetries and environments to deeper investigate the CF parameters origin.

\section{Acknowledgements}

F.G and B.L.G thank the French GENCI/IDRIS-CINES center for high-performance computing resources. F.G. and B.L.G. acknowledge the Stratégie d'Attractivité Durable (SAD18006-LnCPLSMM). Authors acknowledge support from Agence Nationale de la Recherche (SMMCPL ANR-19-CE29-0012-02) and the European Research Council under the European Union's Horizon 2020 research and innovation program (ERC-CoG MULTIPROSMM, Grant agreement No. 725184). All authors are indebted to J.-H. van Veck for illuminating the richness and complexity of lanthanide optical spectra.

\section{References}

1 a) J. D. Rinehart and J. R. Long, Exploiting single-ion anisotropy in the design of f-element single-molecule magnets, Chem. Sci. 2011, 2, 2078-2085; b) D. N. Woodruff, R. E. P. Winpenny and R. A. Layfield, Lanthanide Single-Molecule Magnets, Chem. Rev., 2013, 113, 5110-5148; c) Z. Zhu, M. Guo, X.-L. Li and J. Tang, Molecular magnetism of lanthanide: Advances and perspectives, Coord. Chem. Rev. 2019, 378, 350-364; d) O. Cador, B. Le Guennic and F. Pointillart, Electro-Activity and Magnetic Switching in Lanthanide-Based Single-Molecule Magnets, 
Inorg. Chem. Front. 2019, 6, 3398-3417; e) M. J. H. Ojea, L. C. H. Maddock and R. A. Layfield, Lanthanide organometallics as Single-Molecule Magnets, Top. Organomet. Chem. 2019, 64, 253-280; f) L. Escalera-Moreno, J. J. Baldoví, A. Gaita-Ariño and E. Coronado, Exploring the High-Temperature Frontier in Molecular Nanomagnets: From Lanthanides to Actinides, Inorg. Chem. 2019, 58, 11883-11892; g) J. Lu, M. Guo and J. Tang Recent Developments in Lanthanide Single-Molecule Magnets, Chem. Asian J. 2017, 12, 2772-2779.

2 a) C. P. Montgomery, B. S. Murray, E. J. New, R. Pal and D. Parker, Cell-Penetrating Metal Complex Optical Probes: Targeted and Responsive Systems Based on Lanthanide Luminescence, Acc. Chem. Res. 2009, 42, 925937; b) E. G. Moore, A. P. S. Samuel and K. N. Raymond, From Antenna to Assay: Lessons Leamed in Lanthanide Luminescence, Acc. Chem. Res. 2009, 42, 542-552; c) E. J. New, D. Parker, D. G Smith and J. W Walton, Development of Responsive Lanthanide Probes for Cellular Applications, Curr. Opin. Chem. Biol. 2010, 14, 238-246; d) S. V. Eliseeva and J.-C. G. Bünzli, Lanthanide luminescence for functional materials and bio-sciences, Chem. Soc. Rev. 2010, 39, 189-227; e) A. de Bettencourt-Dias, Luminescence of Lanthanide lons in Coordination Compounds and Nanomaterials, John Wiley \& Sons, Ltd, 2014; e) G.-Q. Jin, Y. Ning, J.-X. Geng, Z.-F. Jiang, Y. Wang and J.-L. Zhang, Joining the journey to near infrared (NIR) imaging: the emerging role of lanthanides in the designing of molecular probes, Inorg. Chem. Front., 2020, 7, 289-299; f) N. Hamon, A. Roux, M. Beyler, J.-C. Mulatier, C. Andraud, C. Nguyen, M. Maynadier, N. Bettache, A. Duperray, A. Grichine, S. Brasselet, M. Gary-Bobo, O. Maury and R. Tripier, Pyclen-Based Ln(III) Complexes as Highly Luminescent Bioprobes for In Vitro and In Vivo One- and Two-Photon Bioimaging Applications, J. Am. Chem. Soc. 2020,142, 10184-10197.

3 a) J. P. Riehl and F. S. Richardson, Circularly Polarized Luminescence Spectroscopy, Chem. Rev. 1986, 86, 1-16; b) G. Muller, Luminescent chiral lanthanide(III) complexes as potential molecular probes, Dalton Trans. 2009, 96929707; c) R. Carr, N. H. Evans and D. Parker, Lanthanide complexes as chiral probes exploiting circularly polarized luminescence, Chem. Soc. Rev. 2012, 41, 7673-7686; c) F. Zinna and L. Di Bari, Lanthanide Circularly Polarized Luminescence: Bases and Applications, Chirality 2015, 27, 1-13.

4 a) S. Shuvaev, E. A. Suturina, K. Mason and D. Parker, Chiral probes for $\alpha 1$-AGP reporting by species- specific induced circularly polarised luminescence Chem. Sci. 2018, 9, 2296-3003; b) M. Leonzio, A. Melchior, G. Faura, M. Tolazzi, M. Bettinelli, F. Zinna, L. Arrico, L. Di Bari and F. Piccinelli, A chiral lactate reporter based on total and circularly polarized Tb(iii) luminescence, New J. Chem. 2018, 42, 7931-7939; c) J. Yuasa, T. Ohno, H. Tsumatori, R. Shiba, H. Kamikubo, M. Kataoka, Y. Hasegawa and T. Kawai, Fingerprint signatures of lanthanide circularly polarized luminescence from proteins covalently labeled with a $\beta$-diketonate europium(III) chelate, Chem. Commun. 2013, 49, 4604-4606; d) K. M. Ayers, N. D. Schley and G. Ung, Circularly Polarized Luminescence from Enantiopure $\mathrm{C}_{2-}$ Symmetrical Tetrakis(2-pyridylmethyl)-1,2-diam inocyclohexane Lanthanide Complexes Inorg. Chem. 2020, 59, 76577665.

5 M. Górecki, L. Carpita, L. Arrico, F. Zinna and L. Di Bari, Chiroptical methods in a wide wavelength range for obtaining $\mathrm{Ln}^{3+}$ complexes with circularly polarized luminescence of practical interest, Dalton Trans. 2018, 47, 71667177.

6 F. Zinna, M. Pasini, F. Galeotti, C. Botta, L. Di Bari and U. Giovanella, Design of Lanthanide-Based OLEDs with Remarkable Circularly Polarized Electroluminescence, Adv. Funct. Mater. 2017, 27, 1603719.

7 S. V. Eliseeva and J.-C. G. Bünzli, In Lanthanide spectroscopy, Materials, and Bioapplications; P. Hännen, H. Härmä, Eds.; Springer Series on Fluorescence; Springer Verlag: Berlin, 2010; Vol. 7, Chapter 1.

8 For recent reviews see: a) F. Pointillart, B. le Guennic, O. Cador, O. Maury and L. Ouahab, Lanthanide lon and Tetrathiafulvalene-Based Ligand as a "Magic" Couple Toward Luminescence, Single Molecule Magnet and Magneto- 
Structural Correlations, Acc. Chem. Res. 2015, 48, 2834-2842; b) F. Pointillart, O. Cador, B. Le Guennic and L. Ouahab, Uncommon Lanthanide lons in Purely $4 f$ Single Molecule Magnets, Coord. Chem. Rev. 2017, 346, 150-175; c) J. Long, Y. Guari, R. A. S. Ferreira, L. D. Carlos and J. Larionova, Recent advances in luminescent lanthanide based Single-Molecule Magnets, Coord. Chem. Rev. 2018, 363, 57-70; d) J.-H. Jia, Q.-W. Li, Y.-C. Chen, J.-L. Liu and M.-L. Tong, Luminescent single-molecule magnets based on lanthanides: Design strategies, recent advances and magneto-lumines cent studies, Coord. Chem. Rev. 2019, 378, 365-381; e) R. Marin, G. Brunet and M. Murugesu, Shining new light on multifunctional lanthanide single - molecule magnets, Angew. Chem. Int. Ed. 2020, doi.org/10.1002/anie.201910299.

9 a) G. Cucinotta, M. Perfetti, J. Luzon, M. Etienne, P.-E. Car, A. Caneschi, G. Calvez, K. Bernot and R. Sessoli, Magnetic Anisotropy in a Dysprosium/DOTA Single-Molecule Magnet: Beyond Simple Magneto-Structural Correlations, Angew. Chem. Int. Ed. 2012, 51, 1606-1610; b) M.-E. Boulon, G. Cucinotta, J. Luzon, C. Degl'Innocenti, M. Perfetti, K. Bernot, G. Calvez, A. Caneschi and R. Sessoli, Magnetic Anisotropy and Spin -Parity Effect Along the Series of Lanthanide Complexes with DOTA, Angew. Chem. Int. Ed. 2013, 52, 350-354.

10 a) Y. Bi, C. Chen, Y.-F. Zhao, Y.-Q. Zhang, S.-D. Jiang, B.-W. Wang, J.-B. Han, J.-L. Sun, Z.-Q. Bian, Z.-M. Wang and S. Gao, Thermostability and photoluminescence of Dy(iii) single-molecule magnets under a magnetic field, Chem. Sci. 2016, 7, 5020-5031; b) L. Norel, L. E. Darago, B. Le Guennic, K. Chakarawet, M. I. Gonzalez, J. H. Olshansky, S. Rigaut and J. R. Long, A Terminal Fluoride Ligand Generates Highly Axial Magnetic Anisotropy in Dysprosium Complexes, Angew. Chem. Int. Ed. 2018, 57, 1933-1938; c) F. Guégan, F. Riobé, O. Maury, J. Jung, B. Le Guennic, C. Morell and D. Luneau, Teaching an old molecule new tricks: evidence and rationalisation of the slow magnetization dynamics in [DyTp 2 Acac], Inorg. Chem. Front. 2018, 5, 1346-1353; d) D. Errulat, R. Marin, D. A. Gálico, K. L. M. Harriman, A. Pialat, B. Gabidullin, F. likawa, O. D. D. Couto, J. O. Moilanen, E. Hemmer, F. A. Sigoli and M. Murugesu, A Luminescent Themometer Exhibiting Slow Relaxation of the Magnetization: Toward SelfMonitored Building Blocks for Next- Generation Optomagnetic Devices, ACS Cent. Sci. 2019, 5, 1187-1198.

11 a) F. Pointillart, B. Le Guennic, S. Golhen, O. Cador, O. Maury and L. Ouahab, A Redox-Active Luminescent Ytterbium Based Single Molecule Magnet, Chem. Commun. 2013, 49, 615-617; b) X. Yi, K. Bernot, V. Le Corre, G. Calvez, F. Pointillart, O. Cador, B. Le Guennic, J. Jung, O. Maury, V. Placide, Y. Guyot, T. Roisnel, C. Daiguebonne, O. Guillou, Unravelling the Crystal Structure of Lanthanide-Murexide Complexes: Use of an Ancient Complexometry Indicator as a Near-Infra-Red Emitting Single-lon Magnet, Chem. Eur. J. 2014, 20, 1569 - 1576; c) K. Soussi, J. Jung, F. Pointillart, B. Le Guennic, B. Lefeurre, S. Golhen, O. Cador, Y. Guyot, O. Maury and L. Ouahab, Magnetic and photo-physical investigations into Dy"l' and $\mathrm{Yb}^{\text {III }}$ complexes involving tetrathiafulvalene ligand, Inorg. Chem. Front. 2015, 2, 1105-1117; d) K. S. Pedersen, J. Dreiser, H. Weihe, R. Sibille, H. V. Johannesen, M. A. Sørensen, B. E. Nielsen, M. Sigrist, H. Mutka, S. Rols, J. Bendix and S. Piligkos, Design of Single-Molecule Magnets: Insufficiency of the Anisotropy Barrier as the Sole Criterion, Inorg. Chem. 2015, 54, 7600-7606; e) G. Brunet, R. Marin, M.-J. Monk, U. Resch-Genger, D. A. Gálico, F. A. Sigoli, E. A. Suturina, E. Hemmer and M. Murugesu, Exploring the dual functionality of an ytterbium complex for luminescence themometry and slow magnetic relaxation, Chem. Sci. 2019, 10, 6799-6808; f) F. Guégan, J. Jung, B. Le Guennic, F. Riobé, O. Maury, B. Gillon, J.-F. Jacquot, Y. Guyot, C. Morell, and D. Luneau, Evidencing under-barrier phenomena in a $\mathrm{Yb}(\mathrm{III}) \mathrm{SMM}$ : a joint luminescence/neutron diffraction/ SQUID study, Inorg. Chem. Front. 2019, 6, 3152-3157.

12 D. Guettas, F. Gendron, G. Fernandez Garcia, F. Riobé, T. Roisnel, O. Maury, G. Pilet, O. Cador and B. Le Guennic, Luminescence-Driven Electronic Structure Detemination in a Textbook Dimeric Dy(III)-based Single Molecule Magnet, Chem. Eur. J. 2020, 26, 4389-4395. 
13 a) J. P. Leonard, P. Jensen, T. McCabe, J. E. O'Brien, R. D. Peacock, P. E. Kruger and T. Gunnlaugsson, SelfAssembly of Chiral Luminescent Lanthanide Coordination Bundles, J. Am. Chem. Soc. 2007, 129, 10986-10987; b) K.-N. T. Hua, J. Xu, E. E. Quiroz, S. Lopez, A. J. Ingram, V. A. Johnson, A. R. Tisch, A. de Bettencourt-Dias, D. A. Straus and G. Muller, Structural and Photophysical Properties of Visible- and Near-IR-Emitting Tris Lanthanide(III) Complexes Formed with the Enantiomers of N,N-Bis (1-phenylethyl)-2,6-pyridinedicarboxamide, Inorg. Chem. 2012, 51, 647-660.

14 J.-H. van Veck, The Puzzle of Rare-earth Spectra in Solids, J. Phys. Chem. 1937, 41, 67-80.

15 a) A. Picot, F. Malvolti, B. Le Guennic, P.L. Baldeck, J.A.G. Williams, C. Andraud and O. Maury, Two-photon antenna effect induced in octupolar europium complexes, Inorg. Chem. 2007, 46, 2659-2665; b) A. Picot, C. Feu vrie,

C. Barsu, B. Le Guennic, H. Le Bozec, C. Andraud, L. Toupet and O. Maury, Synthesis, structures, optical properties and TD-DFT studies of donor-p-conjugated dipicolinic acid/ester/amide ligands, Tetrahedron 2008, 64, 399-411.

16 a) L. Di Bari, G. Pintacuda, S. Ripoli and P. Salvadori, Structure of metal adducts of anthracyclines probed by absorption, circular dichroism and paramagnetic NMR Magn. Reson. Chem. 2002, 40, 396-405; b) J. Lisowski, S. Ripoli and L. Di Bari, Axial Ligand Exchange in Chiral Macrocyclic Ytterbium(III) Complexes, Inorg. Chem. 2004, 43, 1388-1394.

17 a) M. Lelli and L. Di Bari, Solution structure and structural rearrangement in chiral dimeric ytterbium(III) complexes determined by paramagnetic NMR and NIR-CD, Dalton Trans. 2019, 48, 882-890; b) L. Di Bari, S. Di Pietro, G. Pescitelli, F. Tur, J. Mansilla and J. M. Saa, [Ln(binolam) $)_{3}$. (OTf) ${ }_{3}$, a New Class of Propeller-Shaped Lanthanide(III) Salt Complexes as Enantioselective Catalysts: Structure, Dynamics and Mechanistic Insight, Chem. Eur. J. 2010, 16, 14190-14201; c) W. Porzio, U. Giovannella, F. Vignali, M. Pasini, S. Destri, A. Mech, S. Di Pietro, L. Di Bari and P. Mineo, Thiophene Based Europium $\beta$-Diketonate Complexes: Effect of the Ligand Structure on the Emission Quantum Yield, Inorg. Chem. 2011, 50, 5417-5429; c) S. Di Pietro and L. Di Bari, The Structure of MLn(hfbc) 4 and a Key to High Circularly Polarized Luminescence, Inorg Chem. 2012, 51, 12007-12014; d) S. Di Pietro, D. Imbert and M. Mazzanti, An efficient triazole-pyridine-bistetrazolate platform for highly luminescent lanthanide complexes, Chem. Commun. 2014, 50, 10323-10326; e) R. Berardozzi, G. Pescitelli, S. Di Pietro, C. Resta, F. P. Ballistreri, A. Pappalardo, G. A. Tomaselli and L. Di Bari, Synthesis, Structural Characterization, and Chiroptical Studies of Bidentate Salen-Type Lanthanide (III) Complexes, Chirality, 2015, 27, 857-863; f) S. Di Pietro, N. Gautier, D. Imbert, J. Pécaut and M. Mazzanti, Versatile pyridine-2,6-bis-tetrazolate scaffolds for the formation of highly luminescent lanthanide complexes, Dalton Trans. 2016, 45, 3429-344.

18 a) I. Bertini and C. Luchinat, NMR of paramagnetic substances, Coord. Chem. Rev. 1996, 150, 1-300; b) S. Di Pietro, S. Lo Piano and L. Di Bari, Pseudocontact shifts in lanthanide complexes with variable crystal field parameters, Coord. Chem. Rev. 2011, 255, 2810-2820.

19 S. De, A. Flambard, D. Garnier, P. Herson, F. H. Köhler, A. Mondal, K. Costuas, B. Gillon, R. Lescouëzec, B. Le Guennic and F. Gendron, Probing the local magnetic structure of the $\left[\mathrm{Fe}^{\mathrm{II}}(\mathrm{Tp})(\mathrm{CN})_{3}\right]^{-}$building block via Solid-State NMR, Polarized Neutron Diffraction and First Principle Calculations, Chem. Eur. J. 2019, 25, 12120-12136.

20 A. Abragam and B. Bleaney, Electron Paramagnetic Resonance of Transition lons, Clarendon Press. Oxford, 1970.

$21 \mathrm{X}$. Zou and H. Toratani, Evaluation of spectroscopic properties of $\mathrm{Yb}^{3+}$-doped glasses, Phys. Rev. B 1995, 52, 15889-15897.

22 C. Reinhard and H. U. Gudel, High-Resolution Optical Spectros copy of $\mathrm{Na}_{3}\left[\mathrm{Ln}(\mathrm{dpa})_{3}\right] \cdot 13 \mathrm{H}_{2} \mathrm{O}$ with $\mathrm{Ln}=\mathrm{Er}^{3+}, \mathrm{Tm}^{3+}$, $\mathrm{Yb}^{3+}$, Inorg. Chem. 2002, 41, 1048-1055. 
23 F. Silva, O. L. Malta, C. Reinhard, H. U. Gudel, C. Piguet, J. E. Moser and J. C. G. Bunzli, Visible and NearInfrared Luminescence of Lanthanide-Containing Dimetallic Triple-Stranded Helicates: Energy Transfer Mechanisms in the Sm"' and Yb"I' Molecular Edifices, J. Phys. Chem. A. 2002, 106, 1670-1677.

24 A. T. Bui, M. Beyler, A. Grichine, A. Duperray, J.-C. Mulatier, Y. Guyot, C. Andraud, R. Tripier, S. Brasselet and O. Maury, Near infrared two photon imaging using a bright cationic $\mathrm{Yb}(\mathrm{III})$ bioprobe spontaneously internalized into live cells, Chem. Commun. 2017, 53, 6005-6008.

25 G. Lapadula, A. Bourdolle, F. Allouche, M. Conley, I. del Rosa, L. Maron, W. W. Lukens, Y. Guyot, C. Andra ud, S.

Brasselet, C. Copéret, O. Maury and R. A. Andersen, Near-IR Two Photon Microscopy Imaging of Silica Nanoparticles Functionalized with Isolated Sensitized Yb(III) Centers, Chem. Mater. 2014, 26, 1062.

26 M. Górecki, L. Carpita, L. Arrico, F. Zinna and L. Di Bari, Chiroptical methods in a wide wavelength range for obtaining $\mathrm{Ln}^{3+}$ complexes with circularly polarized luminescence of practical interest, Dalton Trans. 2018, 47, 71667177.

27 A.T. Frawley, R. Pal and D. Parker, Very bright, enantiopure europium(III) complexes allow time-gated chiral contrastimaging, Chem. Commun.2016, 52, 13349.

28 a) L. Guy, M. Mosser, D. Pitrat, J.-C. Mulatier, M. Kukulka, M. Srebo-Hooper, E. Jeanneau, A. Bensalah-Ledoux, B. Baguenard, S. Guy, Modulation of Chiroptical Properties in a Series of Helicene-like Compounds, J. Org. Chem. 2019, 84, 10870-10876; b) A.T. Frawley, R. Pal and D. Parker, Very bright, enantiopure europium(III) complexes allow time-gated chiral contrast imaging, Chem. Commun. 2016, 52, 13349-13353; c) L. E. MacKenzie, L.-O. Pålsson, D. Parker, A. Beeby and R. Pal, Rapid time-resolved Circular Polarization Luminescence (CPL) emission spectroscopy, Nat Commun 2020, 11, 1676.

29 For selected recent examples see: a) E. Kreidt, L. Arrico, F. Zinna, L. Di Bari, and M. Seitz, Circularly Polarised Luminescence in Enantiopure Samarium and Europium Cryptates, Chem. Eur. J. 2018, 24, 13556 - 13564; b) J. Yuasa, T. Ohno, K. Miyata, H. Tsumatori, Y. Hasegawa and T. Kawai, Noncovalent Ligand-to-Ligand Interactions Alter Sense of Optical Chirality in Luminescent Tris( $\beta$-diketonate) Lanthanide(III) Complexes Containing a Chiral Bis (oxazolinyl) Pyridine Ligand, J. Am. Chem. Soc. 2011, 133, 9892-9902; c) M. Leonzio, A. Melchior, G. Faura, M. Tolazzi, F. Zinna, L. Di Bari and F. Piccinelli, Strongly Circularly Polarized Emission from Water-Soluble Eu(III)- and Tb(III)-Based Complexes: A Structural and Spectroscopic Study, Inorg. Chem . 2017, 56, 4413-4421.

30 a) C. L. Maupin, D. Parker, J. G. Williams and J. P. Riehl, Circularly Polarized Luminescence from Chiral Octadentate Complexes of Yb(III) in the Near-Infrared, J. Am. Chem. Soc. 1998, 120, 10563-10564; b) R. S. Dickins, J. A. Howard, C. L. Maupin, J. M. Moloney, D. Parker, J. P. Riehl, G. Siligardi and J. G. Williams, Synthesis, TimeResolved Luminescence, NMR Spectroscopy, Circular Dichroism and Circularly Polarised Luminescence Studies of Enantiopure Macrocyclic Lanthanide Tetraamide Complexes, Chem. Eur. J., 1999, 5, 1095-1105; c) C. L. Maupin, C. L. Dickins, L. G. Govenlock, C. E. Mathieu, D. Parker, J. A. G. Williams and J. P. Riehl, The Measurement of Circular Polarization in the Near-IR Luminescence from Chiral Complexes of $\mathrm{Yb}(\mathrm{III})$ and $\mathrm{Nd}(\mathrm{III})$, J. Phys. Chem. A 2000, 104, 6709-6717; d) F. Zinna, L. Arrico and L. Di Bari, Near-infrared circularly polarized luminescence from chiral Yb(III)diketonates, Chem. Commun. 2019, 55, 6607-6609.

31 a) F. Gendron, D. Paez-Hernandez, F.-P. Notter, B. Pritchard, H. Bolvin and J. Autschbach, Magnetic Properties and Electronic Structure of Neptunyl(VI) Complexes: Wavefunctions, Orbitals, and Crystal-Field Models, Chem. Eur. J. 2014, 20, 7994-8011; b) F. Gendron, B. Pritchard, H. Bolvin and J. Autschbach, Single-ion 4 f element magnetism: an ab-initio look at Ln(COT) $2^{-}$, Dalton Trans. 2015, 44, 19886-19900; c) F. Gendron, H. Bolvin and J. Autschbach, 
Complete Active Space Wavefunction-Based Analysis of Magnetization and Electronic Structure, Top. Organomet. Chem. 2019, 64, 355-390.

32 R. Berardozzi, L. Di Bari, Optical Acti vity in the Near-IR Region: The I=980 nm Multiplet of Chiral $\mathrm{Yb}^{3+}$ Complexes, ChemPhysChem 2015, 16, 2868-2875.

33 F. Gendron, B. Moore II, O. Cador, F. Pointillart, J. Autschbach, B. Le Guennic, Ab-Initio Study of Circular Dichroism and Circularly Polarized Luminescence of Spin-allowed and Spin-forbidden Transitions: From Organic Ketones to Lanthanide Complexes, J. Chem. Theory. Comput. 2019, 15, 4140-4155.

34 K. Binnemans, L. Malykhina, V. S. Mironov, W. Haase, K. Driesen, R. Van Deun, L. Fluyt, C. Görller-Walrand and Y. G. Galyametdinov, Probing the Magnetic Anisotropy of Lanthanide-Containing Metallomesogens by Luminescence Spectroscopy, ChemPhysChem, 2001, 2, 680-683.

35 a) M. Autillo, L. Guerin, T. Dumas, M. S. Grigoriev, A. M. Fedoseev, S. Cammelli, P. L. Solani, D. Guillaumont, P. Guilbaud, P. Moisy, H. Bolvin and C. Berthon, Insight of the Metal-Ligand Interaction in f-Element Complexes by Paramagnetic NMR Spectroscopy, Chem. Eur. J. 2019, 25, 4435-4451; b) J. Jung, M. A. Islam, V. L. Pecoraro, T. Mallah, C. Berthon and H. Bolvin, Derivation of Lanthanide Series Crystal Field Parameters From First Principles, Chem. Eur. J. 2019, 25, 15112-15122.

36 During the course of the reviewing process of the present work, low-temperature CPL measurements in the visible region of a Dy(III) complexwere proposed (https://doi.org/10.1039/d0qi00919a). 